\title{
Current Research on Antiepileptic Compounds
}

\author{
Cheng-Xi Wei ${ }^{1,+}$, Ming Bian ${ }^{1,+}$ and Guo-Hua Gong ${ }^{1,2, *}$ \\ Received: 29 July 2015 ; Accepted: 6 November 2015 ; Published: 20 November 2015 \\ Academic Editor: Derek J. McPhee \\ 1 Medicinal Chemistry and Pharmacology Institute, Inner Mongolia University for the Nationalities, \\ Tongliao 028000, China; weichengxi1224@163.com (C.-X.W.); xiaopang1224@126.com (M.B.) \\ 2 Affiliated Hospital of Inner Mongolia University for Nationalities, Tongliao 028000, Inner Mongolia, China \\ * Correspondence: gongguohua0211@163.com; Tel./Fax: +86-475-831-4245 \\ + These authors contributed equally to this work.
}

\begin{abstract}
Epilepsy affects about $1 \%$ of the world's population. Due to the fact all antiepileptic drugs (AEDs) have some undesirable side effects and about $30 \%$ of epileptic patients are not seizure-free with the existing AEDs, there is still an urgent need for the development of more effective and safer AEDs. Based on our research work on antiepileptic compounds and other references in recent years, this review covers the reported work on antiepileptic compounds which are classified according to their structures. This review summarized 244 significant anticonvulsant compounds which are classified by functional groups according to the animal model data, although there are some limitations in the data. This review highlights the properties of new compounds endowed with promising antiepileptic properties, which may be proven to be more effective and selective, and possibly free of unwanted side effects. The reviewed compounds represent an interesting possibility to overcome refractory seizures and to reduce the percentage of patients with a poor response to drug therapy.
\end{abstract}

Keywords: epilepsy; antiepileptic compounds; structure activity relationship

\section{Introduction}

Epilepsy is one of the more common and frequent neurological disorders in man, characterized by excessive temporary neuronal discharges resulting in uncontrolled convulsions that affect more than 2 million Americans and 60 million people worldwide [1]. If not treated, it is associated with progressively impaired cognition and function, brain damage, and other neurologic deficits. Although in many cases, epilepsy can be adequately controlled through administration of antiepileptic drugs (AEDs), it is estimated that roughly $20 \%-30 \%$ of patients have seizures that are resistant to available medical therapies [2-4].

Conventional AEDs like phenobarbital, primidone, phenytoin, carbamazepine, ethosuximide and the benzodiazepines are widely used. All currently approved antiepileptic drugs have dose-related toxicity and idiosyncratic side effects [5-11]. Therefore, the search for a newer, more effective, more selective agent with lesser side effects continues to be an area of investigation of medicinal chemists worldwide.

Anticonvulsant activities of new synthesized compounds were evaluated according to the Antiepileptic Drug Development Program of the National Institutes of Health (NIH) with the maximal electroshock (MES) test, the subcutaneous pentylenetetrazol (sc-PTZ) test, and the neurotoxicity was evaluated by the rotarod neurotoxicity test. 


\section{The Quinoline Functional Group}

Quinoline is nitrogen-containing heterocyclic aromatic compound. Pharmacologically active substances display a broad range of biological activity. Quinoline has been found to possess anti-malarial, antibacterial, antifungal, anthelmintic, cardiotonic, anticonvulsant, anti-inflammatory, and analgesic activity. Our laboratory has studied a lot of quinoline derivatives for antiepileptic activity [12-23].

Xie et al., reported a new series of 7-alkoxyl-4,5-dihydro-[1,2,4]triazolo[4,3-a]quinoline derivatives. Their anticonvulsant activities were evaluated by the MES test and the sc-PTZ test, and their neurotoxicity was evaluated by the rotarod neurotoxicity test with a median toxic dose $\left(\mathrm{TD}_{50}\right.$ ) value of $54.5 \mathrm{mg} / \mathrm{kg}$, MES and sc-PTZ tests showed that compound 1 (Table 1 ) was the most potent of this series with an effective dose $\left(\mathrm{ED}_{50}\right)$ value of 11.8 and $6.7 \mathrm{mg} / \mathrm{kg}$ and protective index $\left(\mathrm{PI}=\mathrm{TD}_{50} / \mathrm{ED}_{50}\right)$ value of 4.6 and 8.1 , respectively [12].

Table 1. Quinoline anticonvulsant compounds.

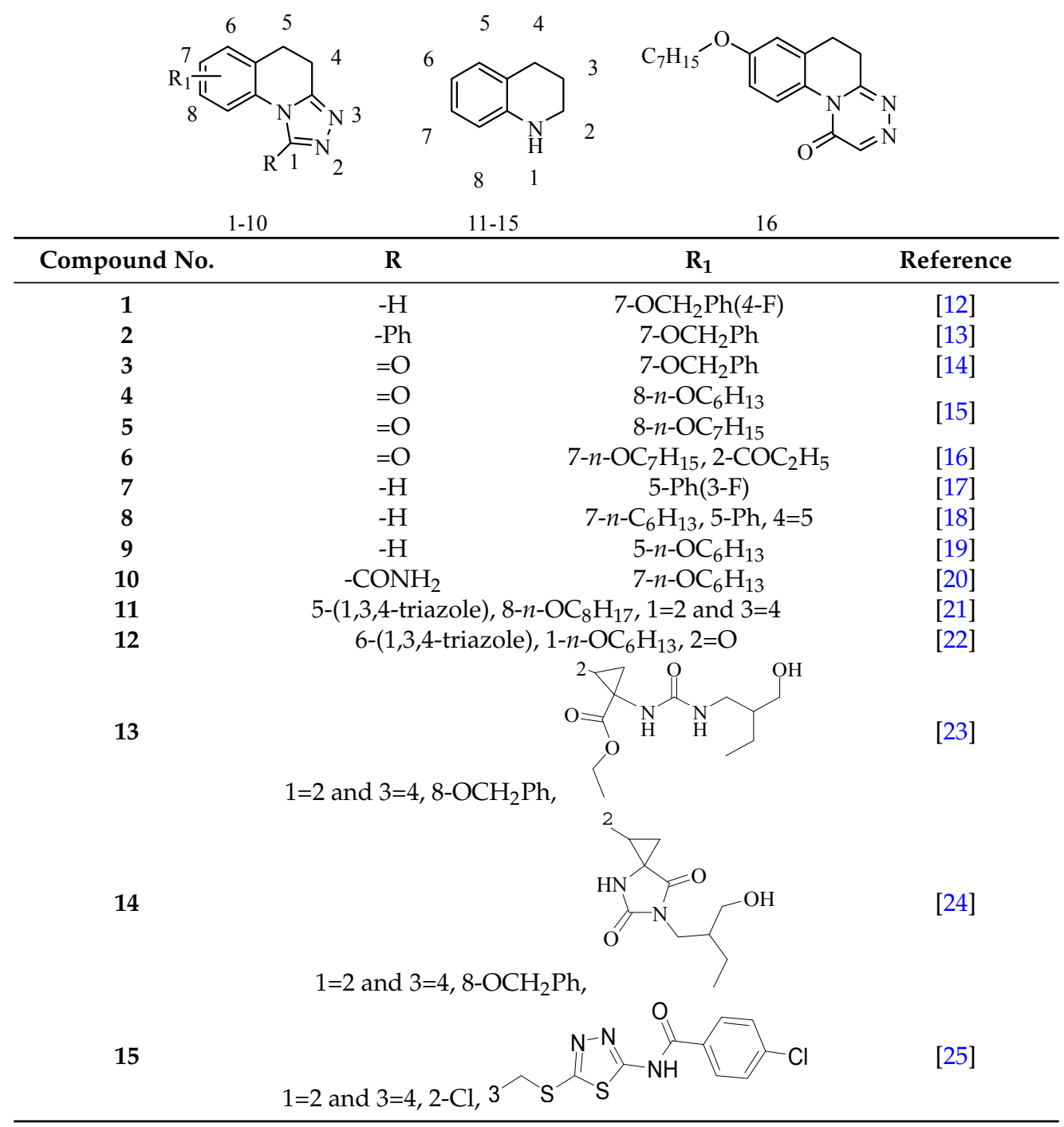

Cui et al., reported a synthesis of 1-substituted-7-benzyloxy-4,5-dihydro-[1,2,4]triazolo[4,3-a]quinolines. Anticonvulsant activity was evaluated in the MES test, sc-Met test, and rotarod neurotoxicity test. The safest compound was 2 (Table 1), with $\mathrm{TD}_{50}$ values of greater than $300 \mathrm{mg} / \mathrm{kg}$ which was better than most of the market drugs [13]. 
Jin et al., prepared a novel type of 7-hydroxyl-3,4-dihydro-2(1H)-quinolines. In the anti-MES test, compound 3 showed $\mathrm{ED}_{50}$ of $12.3 \mathrm{mg} / \mathrm{kg}$ (Table 1), TD 50 of $547.5 \mathrm{mg} / \mathrm{kg}$, and the PI of 44.5 which was much greater than the PI of the reference drugs phenytoin, phenobarbital, carbamazepin and valproate [14]. Sun et al., reported the synthesis of 8-alkoxy-4,5-dihydro-[1,2,4]triazole[4,3-a]quinoline-1-one derivatives and evaluated their anticonvulsant activities by MES test, sc-PTZ test, and rotarod test. The results demonstrated that compound 4 and compound $\mathbf{5}$ were the most potent anticonvulsants (Table 1), with $\mathrm{ED}_{50}$ values of $17.17 \mathrm{mg} / \mathrm{kg}$ and $24.55 \mathrm{mg} / \mathrm{kg}$ and PI values of 41.9 and $29.3 \mathrm{of}$ compound 4 in the MES and sc-PTZ tests, respectively, and compound 5 having $\mathrm{ED}_{50}$ values of $19.7 \mathrm{mg} / \mathrm{kg}$ and $21.2 \mathrm{mg} / \mathrm{kg}$ and PI values of 36.5 and 33.9 in the MES and sc-PTZ tests, respectively. The PI values of compounds $\mathbf{4}$ and $\mathbf{5}$ were many folds better than that of the reference drugs which mentioned above, which have PI values in the range of 1.6-8.1 in the MES test and $<0.22-5.2$ in the sc-PTZ test [15].

Wei et al., synthesized a series of 2-substituted-7-heptyloxy-4,5-dihydro-[1,2,4]triazolo[4,3-a]quinolin-1(2H)-ones and evaluated their anticonvulsant activities. Pharmacological tests showed that compound 6 was the most active and also had the lowest toxicity (Table 1). In the anti-MES test, it showed $\mathrm{ED}_{50}$ of $8.2 \mathrm{mg} / \mathrm{kg}, \mathrm{TD}_{50}$ of $318.3 \mathrm{mg} / \mathrm{kg}$, and PI of 39.0 which was much greater than the PI of the reference drugs phenytoin and carbamazepine [16].

Guan et al., designed and synthesized a new series of substituted quinoline-2(1H)-one and 1,2,4-triazolo[4,3-a]quinoline derivatives. Their anticonvulsant activities were evaluated by MES test, sc-PTZ test and rotarod test. Compound 7 showed the strongest anticonvulsant effect with $\mathrm{ED}_{50}$ of $27.4 \mathrm{mg} / \mathrm{kg}$ and $22.0 \mathrm{mg} / \mathrm{kg}$ in the anti-MES and anti-PTZ test, respectively (Table 1) [17].

Guan et al., reported the synthesis of a series of novel 5-phenyl-[1,2,4]triazolo[4,3-a]quinoline derivatives and evaluated their anticonvulsant activities. The MES test showed that compound 8 was found to be the most potent compound with an $\mathrm{ED}_{50}$ value of $6.5 \mathrm{mg} / \mathrm{kg}$ and a PI value of 35.1 which was much higher than the PI of the reference drug phenytoin (Table 1) [18].

Guo et al., synthesized a series of 5-alkoxy-[1,2,4]triazolo[4,3-a]quinoline derivatives. Their anticonvulsant activities were evaluated by MES test and their neurotoxicity was measured by the rotarod test. The results demonstrated that compound 9 was the most potent anticonvulsant (Table 1 ), with $\mathrm{ED}_{50}$ of $19.0 \mathrm{mg} / \mathrm{kg}$ and PI value of 5.8 in the MES test [19].

Sun et al., synthesized a series of 8-alkoxy-5,6-dihydro-[1,2,4]triazino[4,3-a]quinolin-1-one derivatives and evaluated their activities. The results showed that compound $\mathbf{1 0}$ was the most potent with an $\mathrm{ED}_{50}$ value of $11.4 \mathrm{mg} / \mathrm{kg}$ (Table 1), $\mathrm{TD}_{50}$ of $114.1 \mathrm{mg} / \mathrm{kg}$, PI value of 10.0 which is much greater than the PI of the reference drug carbamazepine [20].

Wei et al., established a series of 1-formamidotriazolo[4,3-a]quinoline derivatives and evaluated their anticonvulsant activities. Compound 11 showed an $\mathrm{ED}_{50}$ of $30.1 \mathrm{mg} / \mathrm{kg}$ (Table 1), $\mathrm{TD}_{50}$ of $286 \mathrm{mg} / \mathrm{kg}$, and PI of 9.5 which is greater than the reference drug carbamazepine with the PI value of 6.0 [21].

Wang et al., synthesized two series of 8-alkoxy-5-(4H-1,2,4-triazol-4-yl)quinolines and 8-alkoxy-5-(2H-1,2,4-triazol-3-one-4-yl)quinolines. The anticonvulsant activities of these compounds were evaluated with MES test and rotarod test. Among the synthesized compounds, compound 12 was the most active, with and $\mathrm{ED}_{50}$ of $8.80 \mathrm{mg} / \mathrm{kg}$ (Table 1), $\mathrm{TD}_{50}$ of $176.03 \mathrm{mg} / \mathrm{kg}$ and PI value of 20.0. Its neurotoxicity was the lowest among the synthesized compounds. Meanwhile, it was also significantly lower than carbamazepine that used as reference. Beyond that, the broad spectrum activity of compound $\mathbf{1 2}$ was inferred from the anti-seizure results of bicuculline-, PTZ- and 3-mercaptopropionic acid-induced seizure tests [22].

Deng et al., reported the synthesis of a series of 1-substituted-6-(4H-1,2,4-triazol-4-yl)-3,4dihydroquinolin-2(1H)-ones and screened their anticonvulsant activities. In the MES screening, compound 13 showed anticonvulsant activity in moderation (Table 1). At the dose of $100 \mathrm{mg} / \mathrm{kg}$, all the animals were protected from seizure after treatment with compound $\mathbf{1 3}$, and all compounds synthesized exhibited no neurotoxicity [23]. 
He et al., synthesized 16 new 1-(2-(8-(benzyloxy)quinolin-2-yl)-1-butyrylcyclopropyl)-3substituted urea derivatives and tested their anticonvulsant activity using the MES test and sc-PTZ screening. The most active compound 14 showed anti-MES activity with an $\mathrm{ED}_{50}$ value of $14.3 \mathrm{mg} / \mathrm{kg}$ and $\mathrm{TD}_{50}$ value of $434 \mathrm{mg} / \mathrm{kg}$ after i.p. injection to mice (Table 1), which showed compound 14 with a PI of 30.3 in the MES test [24].

He et al., prepared series of 16 new1-(8-(benzyloxy)quinolin-2-yl-6-substituted-4,6-dia-zaspiro [2,4]heptane-5,7-diones and evaluated their anticonvulsant activities using the MES and sc-PTZ tests. The most active compound 15 showed the MES-induced seizures with $\mathrm{ED}_{50}$ value of $8.6 \mathrm{mg} / \mathrm{kg}$ and $\mathrm{TD}_{50}$ value of $365.3 \mathrm{mg} / \mathrm{kg}$ after i.p. to mice (Table 1), compound 15 with a PI value of 26.8 in the MES test [25].

Kumar et al., demonstrated synthesis of a series of quinoline-incorporated substituted thiadiazole and evaluated their anticonvulsant activity. Compound $\mathbf{1 6}$ showed protection against the MES model at $30 \mathrm{mg} / \mathrm{kg}$ and showed activity at both 0.5 and $4 \mathrm{~h}$ period at dose level of $30 \mathrm{mg} / \mathrm{kg}$ indicating the compound to be highly potent and long acting (Table 1) [26].

\section{The Quinazoline or Quinazolinone Functional Groups}

As new horizons in anticonvulsant therapy, the quinazolines and quinazolinone structural class has been proved to be useful for the design and development of potent anticonvulsant agents [27,28].

Wang et al., synthesized several series of novel 5-alkoxytetrazolo[1,5-a]quinazoline derivatives. Anticonvulsant activities were evaluated using the MES test. Compound $\mathbf{1 7}$ protected completely against MES-induced seizure at a dose of $100 \mathrm{mg} / \mathrm{kg}$ (Table 2), and was the best active compound in this series [29].

Zheng et al., prepared a series of novel 5-phenyl-[1,2,4]triazolo[4,3-c]quinazolin-3-amine derivatives and screened their anticonvulsant activities by the MES test and their neurotoxicity was evaluated by the rotarod neurotoxicity test. The most promising compound was $\mathbf{1 8}$ (Table 2), which showed an $\mathrm{ED}_{50}$ value of $27.4 \mathrm{mg} / \mathrm{kg}$ and a PI value of 5.8. These values were superior to those provided by valproate ( $\mathrm{ED}_{50}$ and PI values of 272 and 1.6, respectively) in the MES test in mice [30].

El-Azab et al., established a new series of 2,3,8-trisubstituted-4 (3H)-quinazoline derivatives. Compounds 19, 20 and 21 displayed median $\mathrm{LD}_{50}$ values of 1000, 418 and $501 \mathrm{mg} / \mathrm{kg}$ with therapeutic index $\left(\mathrm{LD}_{50} / \mathrm{ED}_{50}\right)$ values 10.2, 1.53 and 3.34 (Table 2). Compounds 19, 20 and 21 showed better anticonvulsant activity and much lower toxicity comparable with the reference drugs valproate and methaqualone [31].

El-Azab et al., reported a novel series of 7-substituted-4(3H)-quinazolinone and evaluated their antitumor and anticonvulsant activities. Compounds 22, 23, 24, 25, 26 and 27 showed advanced anticonvulsant activity as well as lower neurotoxicity than reference drugs valproate and methaqualone (Table 2) [32].

Abbas $e t$ al., designed and synthesized a series of 2,3-disubstituted quinazolinone derivatives and a $[1,2,4]$ triazino[2,3-c] quinazolinone and screened their anticonvulsant activity using the sc-PTZ and MES models. The study showed the most active compound 28 had a protective dose $50\left(\mathrm{PD}_{50}\right)$ of $200.53 \mu \mathrm{mol} / \mathrm{kg}\left(\mathrm{PD}_{50}\right.$ of phenobarbitone $\left.=62.18 \mu \mathrm{mol} / \mathrm{kg}\right)($ Table 2$)$ [33].

Rajasekaran et al., synthesized a series of ten novel derivatives of 3-substituted-2thioxoquinazolin-4(3H)-ones. The titled compounds were evaluated for anticonvulsant activities by MES test. The compounds $\mathbf{2 9}$ and $\mathbf{3 0}$ showed potent anticonvulsant activity (Table 2) [34].

Prashanth et al., reported a novel class of $\mathrm{N}$-substituted glycosmicine derivatives and evaluated their anticonvulsant activity by MES test and their neurotoxic effects were determined by rotorod test in mice. The most active compounds $\mathbf{3 1}$ and $\mathbf{3 2}$ exhibited anticonvulsant activity against MES-induced seizure at the dose of $100 \mathrm{mg} / \mathrm{kg}$ (Table 2). Among all compouds 31 and 32 were recorded $70 \%$ of protection [35].

Malik et al., prepared various N-(benzo[d]thiazol-2-ylcarbamoyl)-2-methyl-4-oxoquinazoline-3 $(4 H)$-carbothioamide derivatives and evaluated their anticonvulsant activity with MES and sc-PTZ 
models in mice. The most active one was compound 33 with $\mathrm{ED}_{50}$ value of $82.5 \mathrm{mmol} / \mathrm{kg}$ (MES) and $510.5 \mathrm{mmol} / \mathrm{kg}$ (sc-PTZ) (Table 2). This molecule was more potent than phenytoin and ethosuximide which were used as reference antiepileptic drugs [36].

Saravanan et al., demonstrated some novel quinazolinone derivatives and screened their antiepileptic activity using MES and sc-PTZ seizure tests. The most active one was compound 34 that revealed protection in MES at a dose of $30 \mathrm{mg} / \mathrm{kg}$ (ip) after 0.5 and $4 \mathrm{~h}$ (Table 2). This molecule also provided protection in the sc-PTZ at a dose of $100 \mathrm{mg} / \mathrm{kg}(0.5 \mathrm{~h})$ and $300 \mathrm{mg} / \mathrm{kg} \mathrm{(4} \mathrm{h)} \mathrm{[37].}$

Table 2. Anticonvulsant activity of quinazoline or quinazolinone compounds.<smiles>CCOc1nc2nnnn2c2ccccc12</smiles>

17<smiles>Nc1nnc2c3ccccc3nc(-c3ccccc3Br)n12</smiles>

18

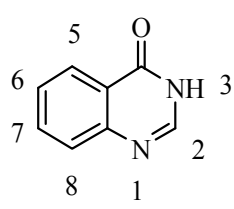

$19-34$

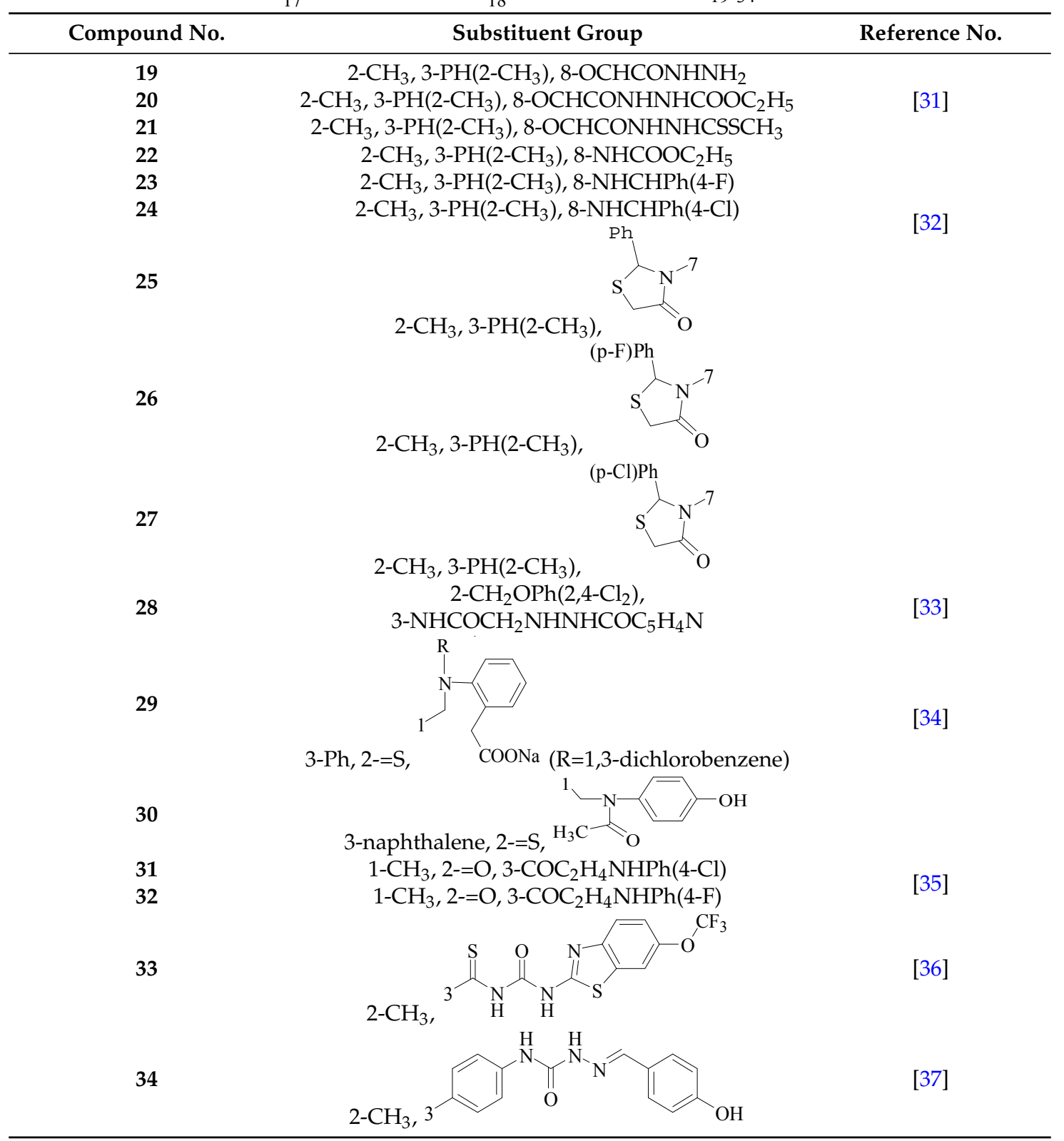




\section{The Thiazole or Benzothiazole Functional Groups}

In the past few decades, the literature has been enriched with progressive findings about the anticonvulsant activities of various substituted thiazole derivatives [38,39].

Siddiqui et al., prepared a series of 1,3-benzothiazol-2-yl-semicarbazones and evaluated their anticonvulsant activity. Compounds 35, 36 and 37 had shown $100 \%$ protection at both the time intervals, that is, 0.5 and $4 \mathrm{~h}$ (Table 3). None of the compounds had shown the sign of neurotoxicity [40].

Table 3. Anticonvulsant thiazole or benzothiazole compounds.

Compound No.

Rana et al., prepared a series of 1,3-benzothiazol-2-yl-benzamides and evaluated their anticonvulsant activity. Compounds 38, 39, 40 emerged as anticonvulsants with no neurotoxicity and can be claimed to detect compounds possessing effects against generalized toniceclonic (grand mal) and generalized absence (petit mal) seizures, respectively (Table 3) [41]. 
Hassan et al., had reported synthesis of a series of $N$-(substituted benzothiazol-2-yl)amide derivatives and evaluated their anticonvulsant effect. Compound $\mathbf{4 1}$ emerged as the most effective, with median doses of $40.96 \mathrm{mg} / \mathrm{kg}\left(\mathrm{MES} \mathrm{ED}_{50}\right), 85.16 \mathrm{mg} / \mathrm{kg}\left(\mathrm{sc}-\mathrm{PTZ} \mathrm{ED}_{50}\right)$ and $347.6 \mathrm{mg} / \mathrm{kg}\left(\mathrm{TD}_{50}\right)$ (Table 3) [42].

Siddiqui et al., demonstrated a synthesis of various $N$-(5-chloro-6-substituted-benzothiazol-2-yl)$N^{\prime}$-(substituted phenyl)-[1,3,4]thiadiazole-2,5-diamines. All the newly synthesized compounds were screened for their anticonvulsant activity and were compared with the standard drug phenytoin sodium. Compounds $\mathbf{4 2}$ and $\mathbf{4 3}$ showed complete protection against MES-induced seizures (Table 3) [43].

Siddiqui et al., also synthesized a series of sulphonamide derivatives and evaluated their possible anticonvulsant activity and neurotoxicity. Compounds $\mathbf{4 4}$ and $\mathbf{4 5}$ were active at lower doses of 100 and $30 \mathrm{mg} / \mathrm{kg}$, respectively, after $4.0 \mathrm{~h}$ (Table 3). Compounds 44 and 45 showed activity at $300 \mathrm{mg} / \mathrm{kg}$ after $4 \mathrm{~h}$ in sc-PTZ screening. Two compounds 44 and 45 showed delayed toxicity that was toxic only after $4.0 \mathrm{~h}$, which were comparable with that of Carbamazepine ( $300 \mathrm{mg} / \mathrm{kg})$ [44].

Farag et al., reported many derivatives of heterocyclic compounds containing a sulfonamide thiazole moiety and evaluated the anticonvulsant effect. Compound 46 obviously showed anticonvulsant activity with no tonic stretching stage and protected all the animals tested (Figure 1) [45].
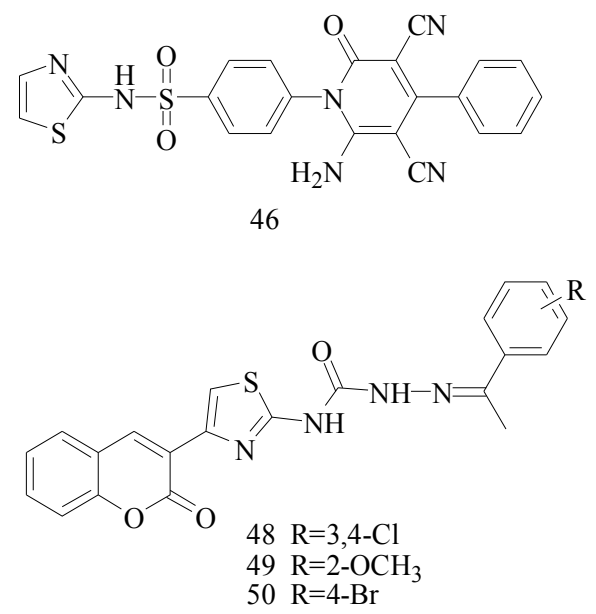

$\mathrm{R}=2-\mathrm{OCH}_{3}$
$\mathrm{O}$

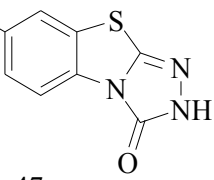

47

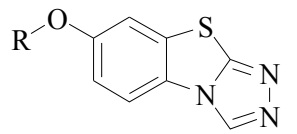

$51 \mathrm{R}=n-\mathrm{C}_{8} \mathrm{H}_{17}$

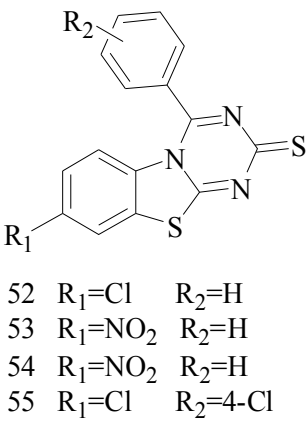

$\begin{array}{lll}54 & \mathrm{R}_{1}=\mathrm{NO}_{2} & \mathrm{R}_{2}=\mathrm{H} \\ 55 & \mathrm{R}_{1}=\mathrm{Cl} & \mathrm{R}_{2}=4-\mathrm{Cl}\end{array}$

Figure 1. Structures of compounds $46-55$.

Siddiqui et al., designed and synthesized several heteroaryl semicarbazones. All synthesized compounds were tested for anticonvulsant activity utilizing pentylenetetrazole-induced seizure (PTZ) and MES tests. Three compounds of the series, 47, 48 and 49, exhibited significant anticonvulsant activity at dose of $30 \mathrm{mg} / \mathrm{kg}$ comparable to the standard drug phenytoin (Figure 1) [46].

Liu et al., established a new series of 7-alkoxy[1,2,4]triazolo[3,4-b]benzothiazol-3(2H)-ones and evaluated their anticonvulsant activities. Compound $\mathbf{5 0}$ was the most active in MES-induced seizure test with $\mathrm{ED}_{50}$ value of $13.6 \mathrm{mg} / \mathrm{kg}$ (Figure 1). Meanwhile, its neurotoxicity was extremely low, with PI > 51 [47].

Deng et al., reported synthesis of 7-alkoxy-triazolo-[3,4-b]benzo[d]thiazoles. In the MES test, most of the compounds synthesized showed good effects on convulsion. Among the compounds studied, compound 51 was found to be the most potent compound with $\mathrm{ED}_{50}$ value of $8.0 \mathrm{mg} / \mathrm{kg}$ and PI value of 15.0 (Figure 1), possessing better anticonvulsant activity and higher safety than market drugs carbamazepine and phenytoin. Compound 51 exhibited activities of broad spectrum in several animal models [48]. 
Siddiqui et al., synthesized a number of new 8 -substituted-4-(2/4-substituted phenyl)-2H-[1,3,5] triazino[2,1-b][1,3]benzothiazole-2-thiones and evaluated their anticonvulsant in a mouse seizure model and were comparable with the standard drug phenytoin. Compounds 52, 53, 54 and 55 showed complete protection after time periods of $0.5 \mathrm{~h}$ and $4 \mathrm{~h}$ (Figure 1) [49].

\section{The Benzothiazines or Benzoxazinone Functional Groups}

Zhang et al., synthesized a novel series of 7-alkoxy-2H-1,4-benzothiazin-3(4H)-ones and a new series of 7 -alkoxy- $4 H$-[1,2,4]triazolo[4,3- $d]$ benzo[ $b][1,4]$ thiazine derivatives. The anticonvulsant activity of these compounds was evaluated by MES test and tarod test following intraperitoneal injection in KunMing mice. Compound 56 was the most active compound, with an $\mathrm{ED}_{50}$ of $17.0 \mathrm{mg} / \mathrm{kg}, \mathrm{TD}_{50}$ of $243.9 \mathrm{mg} / \mathrm{kg}$ and PI of 14.3 (Figure 2). The neurotoxicity was the lowest among the synthesized compounds. Meanwhile, it was also significantly lower than carbamazepine that was used as reference. [50].

Siddiqui et al., reported a series of (Z)-2-(substituted aryl)-N-(3-oxo-4-(substituted carbamothioyl)-3, 4-dihydro-2H-benzo[ $b][1,4]$ oxazin-7-yl)hydrazine carboxamides. The anti-convulsant activity was assessed by the MES test, sc-PTZ test and intraperitoneal thiosemicarbazide test (i.p. TSC). Compounds 57, 58, 59 and 60 were the most active ones, protecting $83 \%-100 \%$ of the animals against MES-induced seizures (Figure 2), and also exhibited potent anticonvulsant activity in chemical-induced seizures [51].

Piao et al., prepared a series of 7-benzylamino-2H-1,4-benzoxazin-3(4H)-ones. Their anticonvulsant activities were evaluated by the MES test and their neurotoxicity was evaluated by the rotarod neurotoxicity test. The MES test showed that compound $\mathbf{6 1}$ was the most potent with $\mathrm{ED}_{50}$ value of $31.7 \mathrm{mg} / \mathrm{kg}$ and PI value of 7.2 (Figure 2) [52].

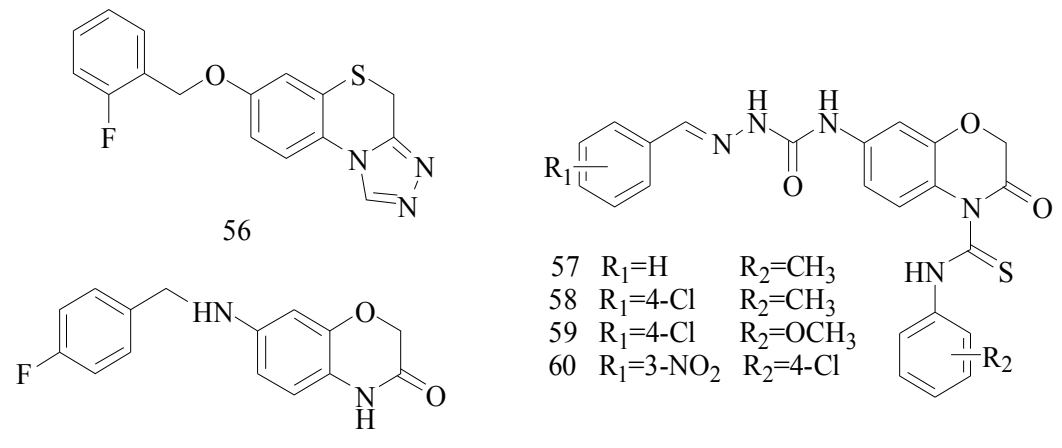

61

Figure 2. Structures of compounds 56-61.

\section{The Oxadiazole or Benzoxazinone Functional Groups}

The oxadiazole scaffold is very versatile and has been subjected to extensive study in recent years. Compounds containing oxadiazole rings have been studied for many biological activities [53].

Bhat et al., prepared a series of 3-(4-acetyl-5H/methyl-5-substituted phenyl-4,5-dihydro-1, 3,4-oxadiazol-2-yl)-2H-chromene-2-ones and evaluated their anticonvulsant activity and neurotoxicity. Compound 62 was found to be potent and had activity at a lower dose of $30 \mathrm{mg} / \mathrm{kg}$ in MES-test (Table 4). All the compounds were less toxic as compared with the standard drug phenytoin [54].

Tabatabai et al., synthesized a series of some derivatives of 2-(2-phenoxy)phenyl-1,3, 4-oxadiazole. Although the most effective compound 63 was a weaker anticonvulsant than diazepam (Table 4), it should be mentioned that it had a good margin of safety and $\mathrm{LD}_{50}$, which were 15 -fold its $\mathrm{ED}_{50}[55]$.

Harish et al., reported a series of novel 1-[5-(4-methoxyphenyl)-[1,3,4]oxadiazol-2-yl]-piperazine derivatives. The anticonvulsant effects of these derivatives on MES-induced seizures were 
experimented in male Wistar rats and phenytoin was used as reference drug. Compounds 64, 65, 66 and 67 showed excellent anticonvulsant activity in MES model (Table 4) [56].

Table 4. Anticonvulsant oxadiazole or benzoxazinone compounds.

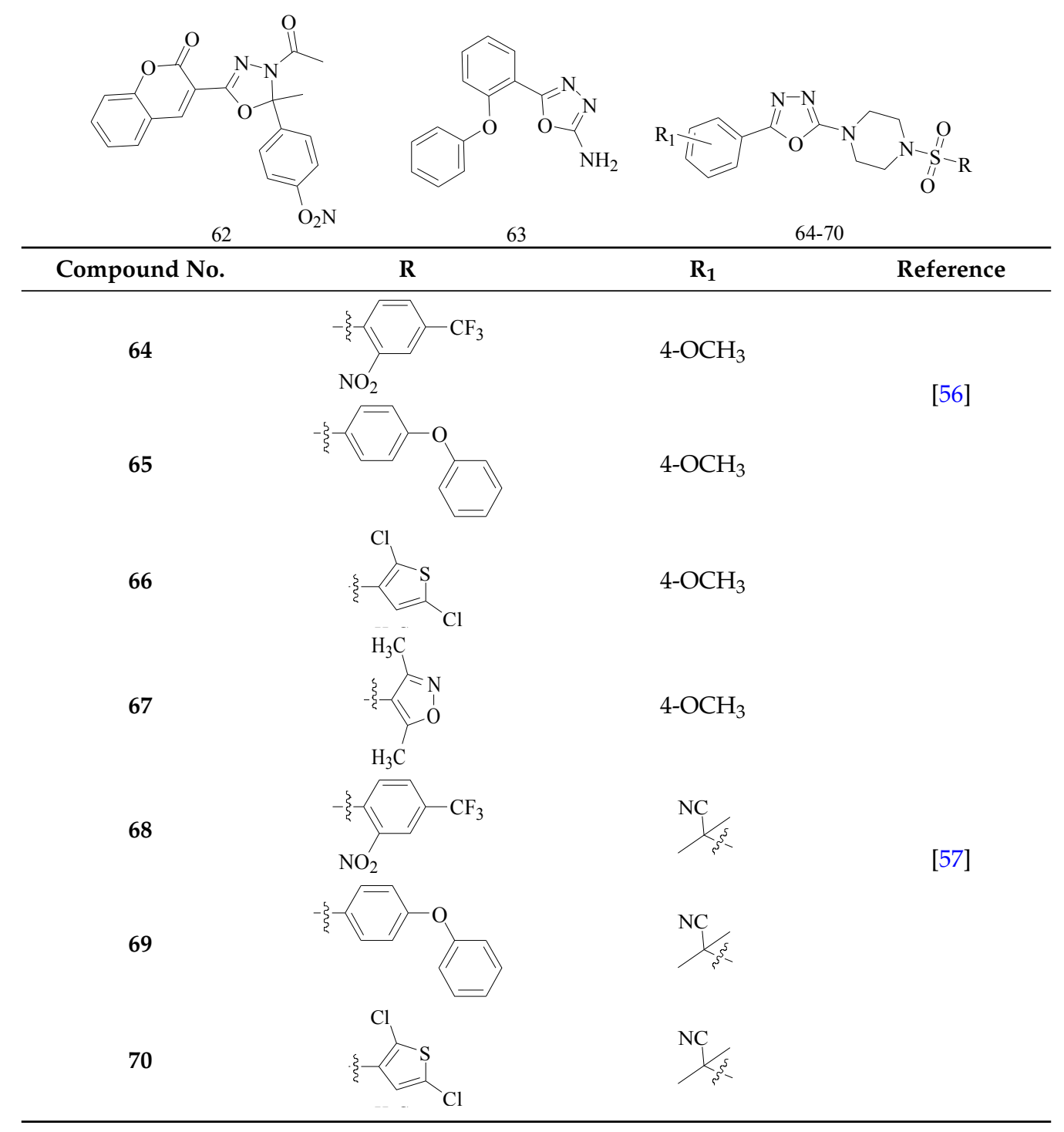

Harish et al., investigated a series of new 2-methyl-2-[3-(5-piperazin-1-yl-[1,3,4]oxadiazol-2-yl)phenyl]-propionitrile derivatives. All the compounds were screened for their anticonvulsant activity against MES seizure and their neurotoxic effects were determined by rotorod test. Compounds 68, 69 and 70 were found to be the most potent of this series (Table 4). These compounds showed no neurotoxicity at the maximum dose administered $(100 \mathrm{mg} / \mathrm{kg})$ [57].

Siddiqui et al., reported a synthesis of new 5-(1H-indol-3-yl)methyl-4-(substituted-aryl)-2, 4-dihydro-3H-1,2,4-triazole-3-thiones. All the newly synthesized compounds were screened for their anticonvulsant activity in the MES model and were compared with the standard drugs phenytoin sodium and carbamazepine. Among these compounds, $\mathbf{7 1}$ was found to be the most active in the series that showed protection against seizures both after $0.5 \mathrm{~h}$ and $4 \mathrm{~h}$ at $30 \mathrm{mg} / \mathrm{kg}$ body mass (Table 4) [58].

Siddiqui et al., designed and synthesized a series of 5-carbomethoxybenzoxazole derivatives. Compounds 72, 73, 74 and 75 were found to be more lipophilic (Figure 3), thus having potent anticonvulsant activity [59]. 
Wei et al., demonstrated a synthesis of novel 2-substituted-6-(4H-1,2,4-triazol-4-yl)benzo[d] oxazoles and evaluated the anticonvulsant activity with the MES test and sc-PTZ test. Compound 76 was the most active and also had the lowest toxicity (Figure 3). In the anti-MES potency test, it showed $\mathrm{ED}_{50}$ of $29.5 \mathrm{mg} / \mathrm{kg}$, a TD 50 of $285 \mathrm{mg} / \mathrm{kg}$, and a PI of 9.7 which was greater than the reference drug, carbamazepine that has a PI of 6.4 [60].

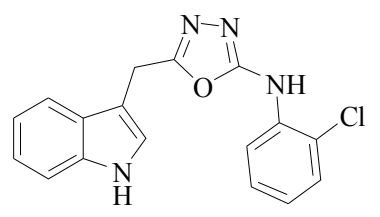

71

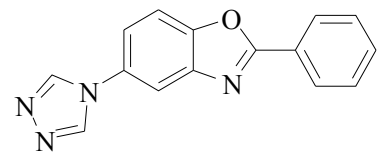

76

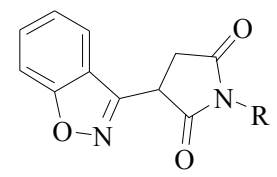

$77 \mathrm{R}=4$-Flouorophenyl $78 \mathrm{R}=$ Cyclohexyl
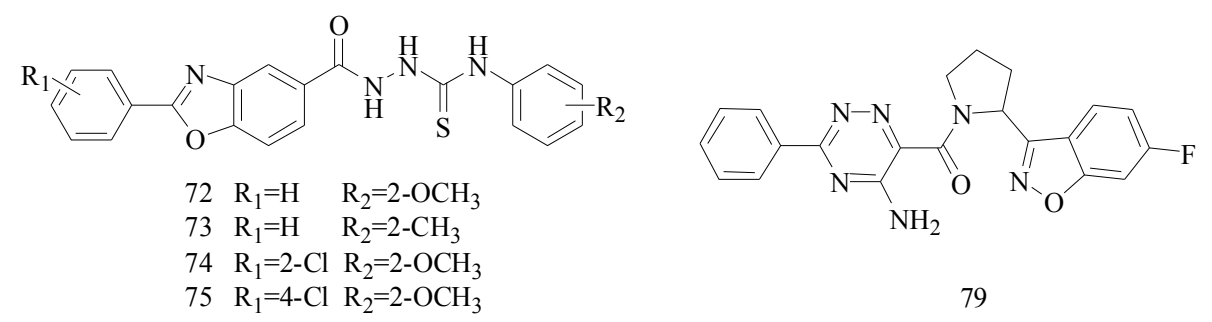

79

Figure 3. Structures of compounds 71-79.

Malik et al., prepared a series of 3-(benzo[d]isoxazol-3-yl)- $N$-substituted pyrrolidine-2,5-dione and evaluated their anticonvulsant activities. Preliminary anticonvulsant activity was performed using MES and sc-PTZ tests after ip injection into mice. $E_{50}$ value of compound 77 was $14.90 \mathrm{mg} / \mathrm{kg}$ (Figure 3). Similarly the most potent one in sc-PTZ was compound 78 with an $\mathrm{ED}_{50}$ value of $42.30 \mathrm{mg} / \mathrm{kg}$ (Figure 3). These compounds were more active and had lower neurotoxicity than the control drugs ethosuximide and phenytoin [61].

Malik et al., synthesized a novel series of (5-amino-3-substituted-1,2,4-triazin-6-yl)(2-(6-halosubstituted-benzo[d]isoxazol-3-yl) pyrrolidin-1-yl)methanone. The MES test showed that compound 79 was the most potent compound (Figure 3), with an $\mathrm{ED}_{50}$ value of $6.20 \mathrm{mg} / \mathrm{kg}$ (oral/rat) and a PI value of $>48.38$ which was much higher than the PI of the reference drug phenytoin [62].

\section{The Pyridine Functional Group}

Pyridines and substituted pyridines are an important family of heterocyclic compounds that has attracted significant interest in medicinal chemistry in recent years [63]. Prasanthi et al., reported synthesis of dialkyl 4-(benzo[d][1,3]dioxol-6-yl)-1,4-dihydro-2,6-dimethyl-1-substituted pyridine-3,5-dicarboxylates. The present study revealed that compound $\mathbf{8 0}$ showed promising anticonvulsant activity compared to phenytoin (Figure 4). Further, the prediction data of the molecular properties supports that compound $\mathbf{8 0}$ might involve hydrogen bonding interaction with target site, and displayed good binding in silico absorption and lower binding rate of plasma to protein, which made it to be a good candidate for treatment of epilepsy [64].

Prasanthi et al., prepared a series of new $N$-diethylmalonyl derivatives of nifedipine and other isosteric analogues. Anticonvulsant screening was performed using sc-PTZ and MES induced seizures. The majority of the compounds were effective in sc-PTZ and MES screening. Compound 81 showed good activity displaying the maximum protection (Figure 4) [65].

Guan LP et al., described a series of new 5-alkoxy-[1,2,4]triazolo[4,3-a]pyridine derivatives and evaluated their anticonvulsant activity and neurotoxicity with the MES and rotarod tests, respectively. The most promising compounds, 82 and $\mathbf{8 3}$ showed $\mathrm{ED}_{50}$ values of 13.2 and $15.8 \mathrm{mg} / \mathrm{kg}$ and had a PI value of 4.8 and 6.9, respectively (Figure 4) [66]. 


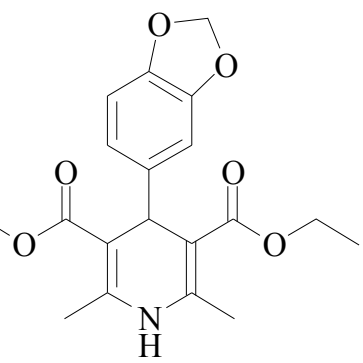

80

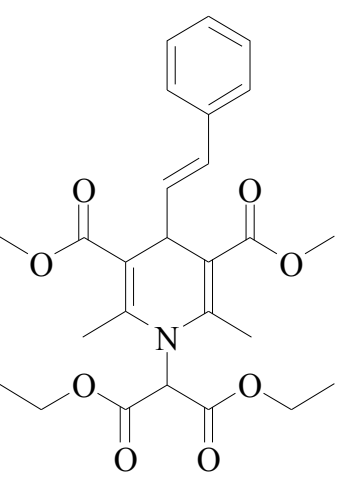

81

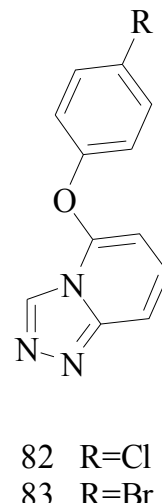

$83 \mathrm{R}=\mathrm{Br}$

Figure 4. Structures of compounds 80-83.

\section{The Pyrazole Functional Group}

Pyrazole and its derivatives consist of five-membered heterocycles with two ortho-nitrogen-atoms. These compounds have received attention in the field of current medicinal and pharmacological research, and are reported to have a broad spectrum of biological activities, such as antitumor, antimicrobial, antioxidant and antimalarial activities [67-70].

Kaushik et al., established synthesis of $N^{\prime}$-[(5-chloro-3-methyl-1-phenyl-1H-pyrazol-4-yl) methylene]2/4-substituted hydrazides and evaluated their anticonvulsant activity against MES- and sc-PTZ-induced seizure models in mice. All compounds showed protection in the MES model at $100 \mathrm{mg} / \mathrm{kg}$, including compound 84 which showed activity at $0.5 \mathrm{~h}$ and $4.0 \mathrm{~h}$ periods indicating that $\mathbf{8 4}$ was potent having a rapid onset and long duration of action (Figure 5). Compound $\mathbf{8 4}$ showed activity at a dose of $100 \mathrm{mg} / \mathrm{kg}$ comparable to sodium valproate in the sc-PTZ test [71].

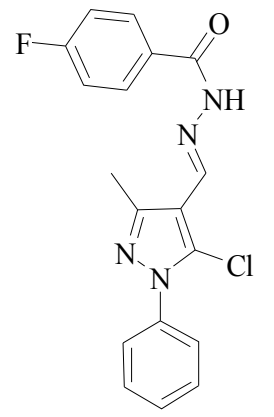

84

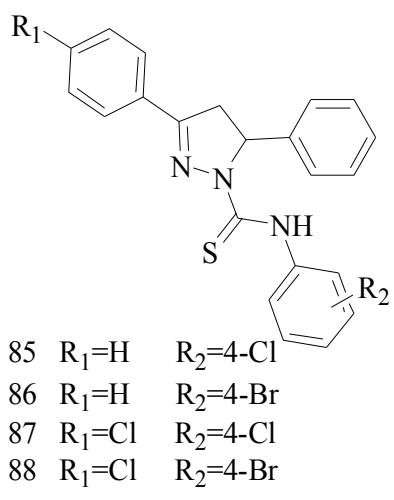

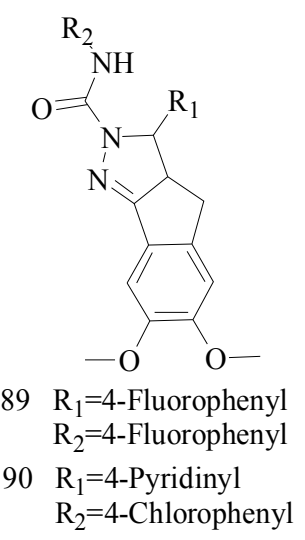

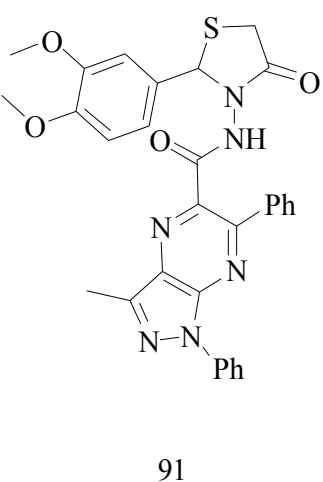

Figure 5. Structures of compounds 84-91.

Siddiqui et al., had reported various 3,5-(substituted-diphenyl)-4,5-dihydro-pyrazole-1-acid phenylamides and evaluated their anticonvulsant activities. Compounds $85,86,87$ and 88 were found to protect $100 \%$ of the animals in the MES screening at a dose of $25 \mathrm{mg} / \mathrm{kg}$ (Figure 5). They were also found to have appreciable anticonvulsant activity in sc-PTZ screening [72].

Ahsan MJ et al., designed and synthesized a series of fourteen 3a,4-dihydro-3H-indeno[1,2-c] pyrazole-2-carboxamide/carbothioamide analogues. Among the compounds synthesized, some exhibited marked effect on seizure model under minimal clonicity ( $6 \mathrm{~Hz}$ psychomotor seizure test). Compound 89 was found to be the most active compound of the series showing $75 \%(3 / 4,0.25-2.0 \mathrm{~h})$ and $50 \%(2 / 4,4.0 \mathrm{~h})$ protection against minimal clonic seizure at $100 \mathrm{mg} / \mathrm{kg}$ without any toxicity 
(Figure 5). Compound 90 showed protection in MES seizure and subcutaneous metrazol (sc-MET) seizure at $300 \mathrm{mg} / \mathrm{kg}$ (Figure 5) [73].

Farghaly A et al., synthesized a series of new pyrazolo[3,4-b]pyrazines containing, 1,2,4-oxadiazolyl, thiadiazolyl, imidazothiadiazolyl, thiazolidinonyl, substituents and other different substituents. Compound 91 showed best results at reducing PTZ-induced tonic convulsions and mortality (Figure 5) [74].

\section{The Imidazole Functional Group}

Imidazole and its derivatives are a class of 5-membered heterocyclic structures having two non-adjacent nitrogen atoms. Recent studies revealed that the substituted imidazole derivatives have attracted much attention due to their broad spectrum of pharmacological activities such as anti-inflammatory, analgesic [75,76]. Literature survey shows that imidazole-heterocyclic compounds could be new classes of anticonvulsant agents by the virtue of their potential anticonvulsant properties [77].

Karakurt et al., described a series of 2-acetylnaphthalene derivatives. Quantification of anti-convulsant protection was calculated via the i.p. route $\left(\mathrm{ED}_{50}\right.$ and $\left.\mathrm{TD}_{50}\right)$ for the most active candidate (92) (Figure 6). Observed protection in the MES model was $38.46 \mathrm{mg} / \mathrm{kg}$ and $123.83 \mathrm{mg} / \mathrm{kg}$ in mice and $20.44 \mathrm{mg} / \mathrm{kg}, 56.36 \mathrm{mg} / \mathrm{kg}$ in rats, respectively [78].<smiles>CC(C)CC(=O)OC(Cn1ccnc1)c1ccc2ccccc2c1</smiles>

92<smiles>COc1ccc(-c2nc(-c3cc(NC(C)=O)ccc3O)cn2-c2ccccc2)cc1OC</smiles>

93<smiles>Cc1ccc(NC(=O)N/N=C(/Cn2ccnc2)c2ccc(Cl)cc2)cc1</smiles>

94

Figure 6. Structures of compounds 92-94.

Husain et al., established a synthesis of a series of 1,2,4-trisubstituted- $1 H$-imidazole derivatives. Anticonvulsant activity was shown by the majority of the synthesized compounds in the MES and $s c$-PTZ screening when given i.p. to mice. In anticonvulsant screening, only one compound, 93, showed potent activity comparable to that of standard drugs phenytoin and carbamazepine (Figure 6) [79].

Amir et al., demonstrated synthesis of a series of novel imidazole incorporated semicarbazones. Compound 94 showed the highest activity among the compounds synthesized with no neurotoxic and depressant effects on CNS (Figure 6). Liver enzyme estimations (serum glutamate oxaloacetate transaminase (SGOT), serum glutamate pyruvate transaminase (SGPT), alkaline phosphatase) of the compound also showed no significant change in the enzyme levels [80].

Ulloora et al., prepared a variety of five new series of imidazo[1,2-a]pyridines carrying biologically active pyrazoline, cyanopyridone, cyanopyridine, 2-aminopyrimidine and pyrimidine-2-thione systems. The target compounds were screened for their in vivo anticonvulsant activity following MES and sc-PTZ methods at a small test dose of $10 \mathrm{mg} / \mathrm{kg}$. Compounds 95, 96, 97, 98, 99 and 100 displayed potent anticonvulsant activity without displaying any toxicity (Table 5) [81].

Ulloora et al., designed and synthesized new 2-arylimidazo[1,2-a]pyridines carrying suitably substituted 1,2,3-triazoles. The anticonvulsant study was carried out by MES and sc-PTZ screening methods, while their toxicity study was performed following rotarod method. The most active was compound 101 which displayed reasonably good activity in both the durations of 0.5 and $4 \mathrm{~h}$ indicating that they possess rapid onset and long duration of action (Table 5). It exhibited complete 
protection against seizure and their activity at $20 \mathrm{mg} / \mathrm{kg}$ was comparable with that of standard drug diazepam [82].

Table 5. Anticonvulsant imidazole compounds.

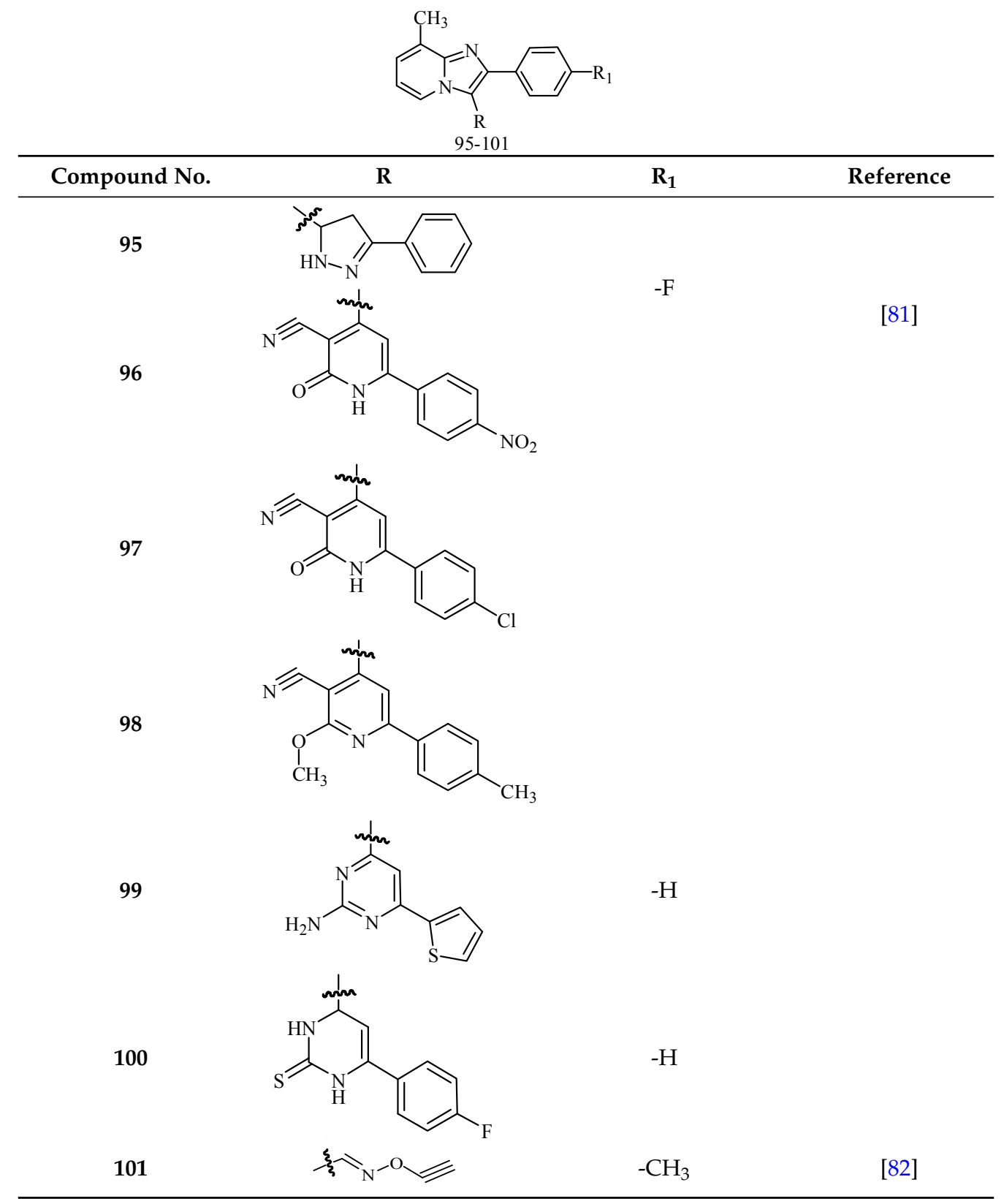

\section{The Pyrimidine Functional Group}

Pyrimidine is an aromatic heterocyclic organic compound similar to pyridine. One of the three diazines, six-membered heterocyclics with two nitrogen atoms in the ring, has the nitrogens at positions 1 and 3 in the ring. Pyrimidines that have a broad spectrum of bioactivities (antibacteria, anticancer and anti-inflammation and so on) are an important one of the heterocyclic compounds [83-85].

Alam et al., synthesized a number of $N$-(4,6-substituted diphenylpyrimidin-2-yl) semicarbazones and tested their anticonvulsant activity against the two seizure models, MES and sc-PTZ. Three compounds $(102,103$ and 104) were found to be significantly active as they showed protection at 
the lowest dose of $30 \mathrm{mg} / \mathrm{kg}$ after $0.5 \mathrm{~h}$ and did not show any sign of neurotoxicity except in case of compound 102 which was found to be neurotoxic at $300 \mathrm{mg} / \mathrm{kg}$ after $4.0 \mathrm{~h}$ (Figure 7) [86].

Deng et al., described the synthesis and anticonvulsant activities of 7-(substituted-phenyl)-6, 7-dihydro-[1,2,4]triazolo[1,5-a]pyrimidin-5(4H)-ones and their derivatives. The majority of the compounds synthesized showed inhibition effects on MES-induced convulsion. The most promising compound 105 showed significant anticonvulsant activity in MES test with ED $_{50}$ value of $19.7 \mathrm{mg} / \mathrm{kg}$ (Figure 7). It was safer than reference drugs with much higher PI value. In addition, the protective effect of compound 105 against seizures induced by PTZ, ISO, TSC, 3-MP, and bicuculline in the chemical-induced seizure tests suggested that compound 103 displayed broad spectrum activity in several models [87].

Jiang et al., reported a novel series of 7-substituted-5-phenyl-[1,2,4]triazolo[1,5- $a]$ pyrimidines. Their anticonvulsant activities were measured through the MES test, and carbamazepine $\left(\mathrm{ED}_{50}=11.8 \mathrm{mg} / \mathrm{kg}\right)$ and valproate $\left(\mathrm{ED}_{50}=272 \mathrm{mg} / \mathrm{kg}\right)$ were used as the reference drugs. Amongst the compounds tested, compound 106 was the most active in inhibiting convulsion with $\mathrm{ED}_{50}$ value of $84.9 \mathrm{mg} / \mathrm{kg}$ that was higher than valproate but lower than carbamazepine (Figure 7) [88].

Shaquiquzzaman et al., established syntheses of some new pyrimidine-5-carbonitrile derivatives. In the MES test, compounds 107, 108 and 109 were found to be highly active at a dose level of $30 \mathrm{mg} / \mathrm{kg}$ at $0.5 \mathrm{~h}$ time interval (Figure 7), indicating their ability to prevent seizure spread at a relatively low dose [89]. Shaquiquzzaman et al., also reported a series of dihydropyrimidine-5-carbonitrile derivatives and evaluated their anticonvulsant activity against MES and sc-PTZ models. Compounds $\mathbf{1 1 0}$ and $\mathbf{1 1 1}$ were found to be most active showing activity both in MES and sc-PTZ screen at lower doses of $30 \mathrm{mg} / \mathrm{kg}$ at $0.5 \mathrm{~h}$ and $100 \mathrm{mg} / \mathrm{kg}$ at $4 \mathrm{~h}$ (Figure 7). In the rotarod motor impairment screen, compound $\mathbf{1 1 0}$ did not show any motor impairment, even at the maximum dose of $300 \mathrm{mg} / \mathrm{Kg}$. The pharmacophore hypothesis also fits best for compounds $\mathbf{1 1 0}$ and 111 [90].
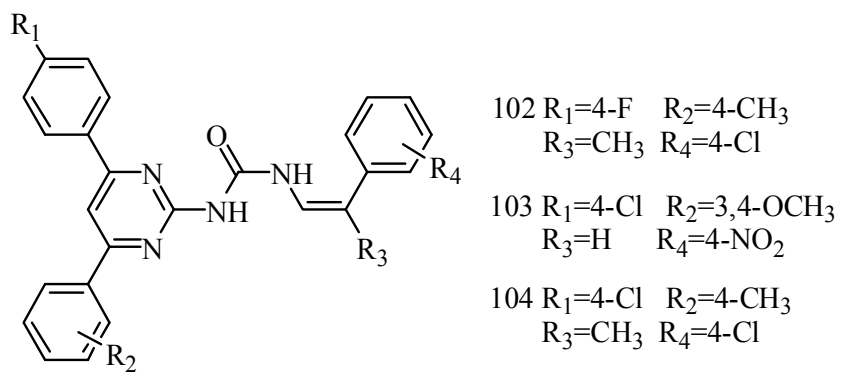<smiles>O=C1CC(c2ccccc2Br)n2ncnc2N1</smiles><smiles>[R]Oc1c(-c2ccccc2)cnc2ncnn12</smiles>

$106 \mathrm{R}=\mathrm{Hept}$<smiles>[R]C(=O)OC([R])(Br)Br</smiles>

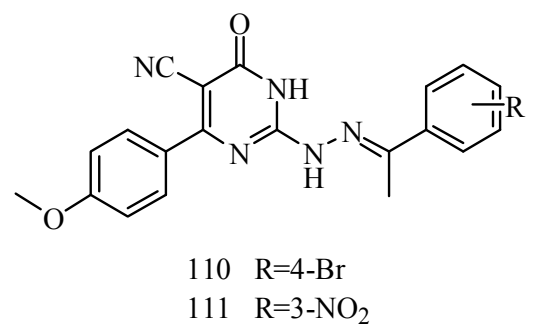

Figure 7. Structures of compounds 102-111.

\section{The Phthalazine Functional Group}

As a heterocyclic compound, the molecular formula of phthalazine is $\mathrm{C}_{8} \mathrm{H}_{6} \mathrm{~N}_{2}$. Because of the broad spectrum of bioactivities such as anticonvulsion, vasorelaxation, anti-inflammation and cardiotonic effect, its derivatives are generally used for treating disease [91-93].

Zhang et al., designed and synthesized a new series of 6-alkoxy-[1,2,4]triazolo[3,4-a] phthalazines and evaluated their anticonvulsant activity and neurotoxicity by the MES test and the rotarod test 
respectively. The most promising compounds $\mathbf{1 1 2}$ and $\mathbf{1 1 3}$ showed a median effective dose of 7.1 and $11.0 \mathrm{mg} / \mathrm{kg}$ (Figure 8), and had protective index values of 5.2 and 8.0, respectively. The two compounds were further found to have potent activity against seizures induced by PTZ, ISO, TSC, 3-MP but not seizures induced by strychnine [94].

Sun et al., investigated a new phthalazine tetrazole derivative. Compound $\mathbf{1 1 4}$ exhibited higher activity $\left(\mathrm{ED}_{50}=6.8 \mathrm{mg} / \mathrm{kg}\right)$ and lower neurotoxicity $\left(\mathrm{TD}_{50}=456.4 \mathrm{mg} / \mathrm{kg}\right)$ (Figure 8$)$, resulting in a higher PI $=67.1$ compared with carbamazepine (PI = 6.4). In addition, compound 114 exhibited significant oral anticonvulsant activity $\left(\mathrm{ED}_{50}=24 \mathrm{mg} / \mathrm{kg}\right)$ against MES-induced seizure with low neurotoxicity $\left(\mathrm{TD}_{50}>4500 \mathrm{mg} / \mathrm{kg}\right.$ ) in mice, resulting in a PI value of more than 187.5 . Compound 114 was also tested in chemically induced animal models of seizure (PTZ, ISO, TSC and 3-MP) to further investigate the anticonvulsant activity. Compound $\mathbf{1 1 4}$ produced significant anticonvulsant activity against seizures induced by ISO, TSC and 3-MP [95].

Bian et al., reported a synthesis of new 6-substituted-[1,2,4]triazolo[3,4-a](tetrazolo[5,1-a]) phthalazine derivatives. All the compounds were evaluated for their anticonvulsant activities using the MES test. The most promising compound $\mathbf{1 1 5}$ showed significant anticonvulsant activity in MES test with $\mathrm{ED}_{50}$ value of $9.3 \mathrm{mg} / \mathrm{kg}$ (Figure 8). It displayed a wide margin of safety with protective index much higher than the standard drug carbamazepine [96].
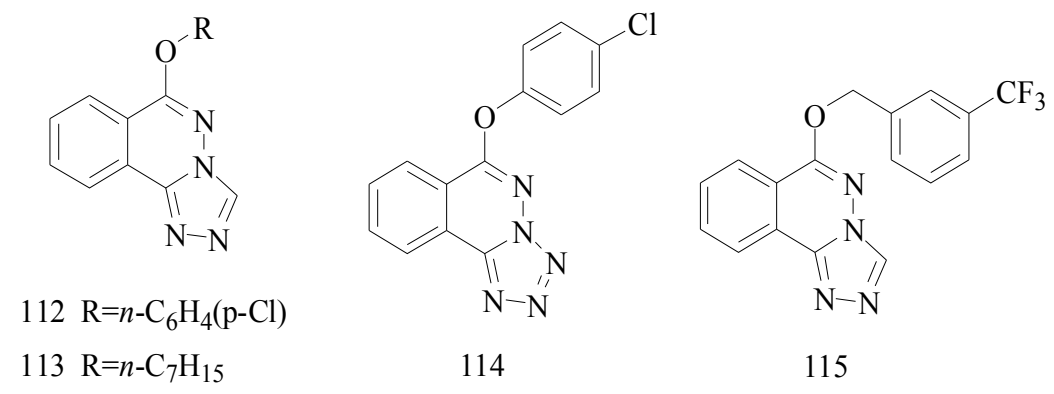

Figure 8. Structures of compounds 112-115.

\section{The Triazine Functional Group}

Triazine is a six membered heterocyclic ring compound containing three nitrogen atoms. The triazine moiety has also attracted the attention of chemists because many triazines are biologically active and are used in medicine, especially as anti-AIDS, anticancer, and antitubercular agents, for their anti-anxiety and anti-inflammatory activities, as well as used in agriculture [97-99].

Kaushik et al., designed and synthesized a new series of 2-(substituted aryloxy)-5-(substituted benzylidene)-3-phenyl-2,5-dihydro-1H-[1,2,4]triazin-6-one. Their anticonvulsant activity was evaluated by MES test, sc-PTZ test. Among the compound tested, compound $\mathbf{1 1 6}$ showed protection from seizures in both the animal models at dose level of $30 \mathrm{mg} / \mathrm{kg}$ (Figure 9). The compound $\mathbf{1 1 6}$ showed activity both at $0.5 \mathrm{~h}$ and $4 \mathrm{~h}$ periods at dose level of $30 \mathrm{mg} / \mathrm{kg}$, indicating the compound to be highly potent and long acting [100].

Amir et al., demonstrated synthesis of new hydrazone incorporated triazines and evaluated for their anticonvulsant activity through MES and sc-PTZ screenings. Among the tested compounds, compound 117 (MES ED 50 54.31, sc-PTZ ED 50 92.01) and compound 118 (MES ED 50 46.05, sc-PTZ ED ${ }_{50}$ 83.90) emerged as the most active anticonvulsant agent having GABA-ergic effects (Figure 9). Compounds $\mathbf{1 1 7}$ and $\mathbf{1 1 8}$ also showed less CNS depressant effect than the standard drug carbamazepine [101].

Ahuja et al., synthesized a series of thirty indole C-3 substituted 5-amino-6(5-substituted-2-phenyl-1H-indol-1-yl)-4,5-dihydro-1,2,4-triazine-3(2H)-thiones. Compound 119 had significant activity in the MES test with minimal duration of limb extension (5.40 $\pm 0.61 \mathrm{~s})$ and 
quantitative median dose of $7 \mathrm{mg} / \mathrm{kg}$. In sc-PTZ screening, compound $\mathbf{1 2 0}$ increased the seizure latency to clonic convulsion and with effective at a median dose of $35 \mathrm{mg} / \mathrm{kg}$ (Figure 9) [102].

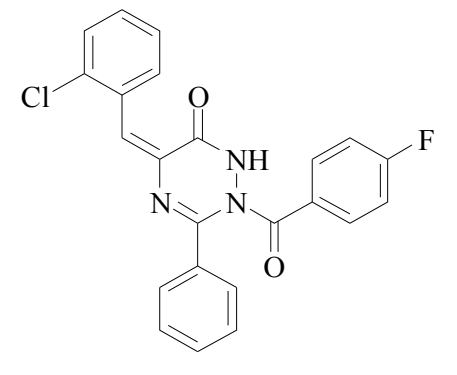

116

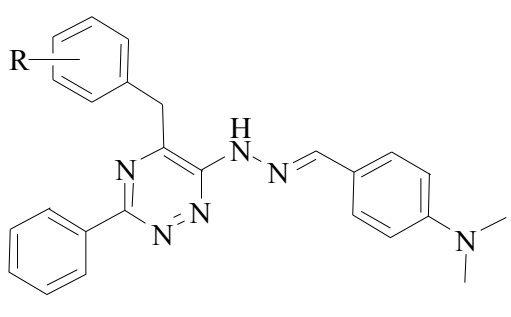

$117 \mathrm{R}=3-\mathrm{Cl}$

$118 \mathrm{R}=4-\mathrm{Cl}$

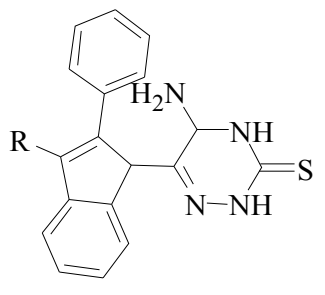

$119 \mathrm{R}=\mathrm{COCH}_{3}$

$120 \mathrm{R}=\mathrm{SO}_{2} \mathrm{NH}_{2}$

Figure 9. Structures of compounds 116-120.

\section{The Triazolethione Functional Group}

Many compounds bearing a triazole moiety were found to possess anticonvulsant properties in various animal models of epilepsy. Therefore, some people want to loop through a combination of triazole-thione compounds to improve the antiepileptic activity.

Luszczki et al., reported the effects of 4-(4-bromophenyl)-5-(3-chlorophenyl)-2,4-dihydro-3H-1,2, 4-triazole-3-thione (compound 121) and 5-(3-chlorophenyl)-4-(4-methylphenyl)-2,4-dihydro-3H-1,2, 4-triazole-3-thione (compound 122) on the protective action of four classical antiepileptic drugs - carbamazepine, phenobarbital, phenytoin and valproate-against MES test in mice (Table 6). Results indicated that compound $\mathbf{1 2 1}$ administered intraperitoneally at doses of 75 and $100 \mathrm{mg} / \mathrm{kg}$ significantly elevated the threshold for electroconvulsions in mice. Compound $121(50 \mathrm{mg} / \mathrm{kg})$ significantly enhanced the anticonvulsant activity of carbamazepine, phenobarbital and valproate. Compound 122 administered intraperitoneally at $10 \mathrm{mg} / \mathrm{kg}$ significantly elevated the threshold for electroconvulsions in mice. Moreover, compound $122(5 \mathrm{mg} / \mathrm{kg})$ significantly enhanced the anticonvulsant activity of valproate, but not that of carbamazepine, phenobarbital or phenytoin in the MES test in mice. Pharmacokinetic experiments revealed that compound $\mathbf{1 2 2}$ significantly elevated total brain concentrations of valproate in mice $[103,104]$.

Table 6. Structures of compounds 121-126.<smiles>[R]n1c(-c2cccc(Cl)c2)n[nH]c1=S</smiles>

$121-124$<smiles>[R]c1ccc(-c2csc(Nc3n[nH]c(=S)n3[R])n2)cc1</smiles>
$125-126$

\begin{tabular}{cccc}
\hline Compound No. & $\mathbf{R}$ & $\mathbf{R}_{\mathbf{1}}$ & Reference \\
\hline $\mathbf{1 2 1}$ & $-\mathrm{Ph}(p-\mathrm{Br})$ & - & {$[103,104]$} \\
$\mathbf{1 2 2}$ & $-\mathrm{Ph}\left(p-\mathrm{CH}_{3}\right)$ & - & \\
$\mathbf{1 2 3}$ & $n-\mathrm{C}_{6} \mathrm{H}_{13}$ & - & {$[105]$} \\
$\mathbf{1 2 4}$ & $-\mathrm{Ph}(p-\mathrm{F})$ & - & {$[106]$} \\
$\mathbf{1 2 5}$ & $-\mathrm{Ph}\left(o-\mathrm{CH}_{3}\right)$ & $-\mathrm{Cl}$ & {$[107]$} \\
$\mathbf{1 2 6}$ & $-\mathrm{Ph}\left(p-\mathrm{OCH}_{3}\right)$ & $-\mathrm{Br}$ & \\
\hline
\end{tabular}

Siddiqui et al., prepared a various of 3-[4-(substituted phenyl)-1,3-thiazol-2-ylamino]-4(substituted phenyl)-4,5-dihydro-1H-1,2,4-triazole-5-thiones. Their in vivo anticonvulsant screenings were performed using the two most adopted seizure models, MES and sc-PTZ. Two compounds, 123 and 124 (Table 6), showed significant anticonvulsant activity in both the screenings with $\mathrm{ED}_{50}$ values of $23.9 \mathrm{mg} / \mathrm{kg}$ and $13.4 \mathrm{mg} / \mathrm{kg}$, respectively, in the MES screen and $178.6 \mathrm{mg} / \mathrm{kg}$ and $81.6 \mathrm{mg} / \mathrm{kg}$, 
respectively, in the sc-PTZ test. They displayed a wide margin of safety with PI, median hypnotic dose $\left(\mathrm{HD}_{50}\right)$ and median lethal dose $\left(\mathrm{LD}_{50}\right)$ which were much higher than that of the standard drugs [105].

Plech et al., designed and synthesized 4-alkyl-1,2,4-triazole-3-thione derivatives. A group of derivatives showed strong anticonvulsant activity. The characteristic features of the most active compounds were rapid onset and long lasting effects. Among the tested compounds, compound 125 was assayed for the different PI values at different preprocessing times (Table 6), and the results of that were ranging from 2.8 to 9.7 [106].

Plech et al., also reported a synthesis of 1,2,4-triazole-3-thione derivatives. Characteristic features of all active compounds were a rapid onset of action and long lasting effects. Compound $\mathbf{1 2 6}$ exhibited the most potent activity $\left(\mathrm{ED}_{50}=35.2 \mathrm{mg} / \mathrm{kg}\right)$ (Table 6) [107].

\section{The Indoline-2,3-dione Functional Group}

Isatin (indoline-2,3-dione), one of the simplest indole derivatives, has led to numerous analogues with a wide range of biological properties, including anxiogenic, sedative, anticonvulsant, anticancer activities [108,109].

Siddiqui et al., designed various 1-(amino- $N$-arylmethanethio)-3-(1-substituted-benzyl-2,3dioxoindolin-5-yl) ureas. Their in vivo anticonvulsant screenings were performed by the two most adopted seizure models, MES and sc-PTZ. At $300 \mathrm{mg} / \mathrm{kg}$, compounds 127 and 128 showed significant protective effect on MES- and sc-PTZ-induced seizures (Figure 10). Even at the lower dose of $100 \mathrm{mg} / \mathrm{kg}$, compound 128 exhibited good protection on MES-induced seizure. These two compounds exhibited marked protective effect against seizures in a $6 \mathrm{~Hz}$ psychomotor seizure test, and could be used as lead compounds for future investigations [110].

Prakash et al., prepared a series of 1-(substituted benzylidene)-4-(1-(morpholino/piperidino methyl)-2,3-dioxoindolin-5-yl) semicarbazides. The compounds were subjected to in vivo antiepileptic evaluation using MES and sc-PTZ test methods. The neurotoxicity was determined by rotarod test. Among the synthesized compounds, $\mathbf{1 2 9}$ revealed excellent protection in both models with lower neurotoxicity (Figure 10) [111].
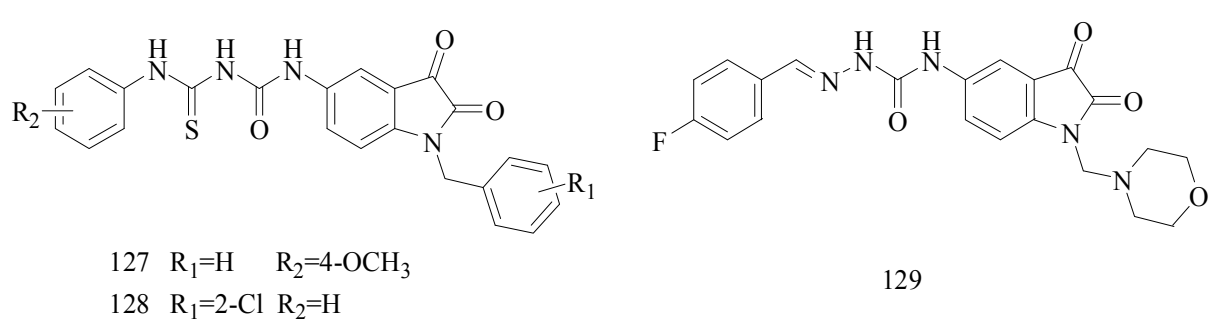

$127 \quad \mathrm{R}_{1}=\mathrm{H} \quad \mathrm{R}_{2}=4-\mathrm{OCH}_{3}$

Figure 10. Structures of compounds 127-129.

\section{The Cyclopropanecarboxylate Functional Group}

He et al., synthesized twenty three 1-(2-arylhydrazinecarboxamido)-2,2-dimethylcyclopropanecarboxylate derivatives and tested their anticonvulsant activity using the MES, sc-PTZ screens. Their neurotoxicity was determined by applying the rotorod test. The most active compound $\mathbf{1 3 0}$ showed protection against the MES-induced seizures with $\mathrm{ED}_{50}$ value of $9.8 \mathrm{mg} / \mathrm{kg}$ and $\mathrm{TD}_{50}$ value of $332.2 \mathrm{mg} / \mathrm{kg}$ after i.p. to mice (Figure 11), which provided compound $\mathbf{1 2 8}$ with a PI of 33.9 in the MES test [112].

Zhong et al., reported fourteen ethyl 2,2-dimethyl-1-(2-substituted-hydrazinecarboxamido) cyclopropanecarboxylate derivatives and tested the anticonvulsant activity using the MES, sc-PTZ screens. The most active compound $\mathbf{1 3 1}$ showed protection against MES-induced seizures with an $\mathrm{ED}_{50}$ value of $9.2 \mathrm{mg} / \mathrm{kg}$ and $\mathrm{TD}_{50}$ value of $387.5 \mathrm{mg} / \mathrm{kg}$ after i.p. to mice (Figure 11), which provided compound 129 with a PI of 42.1 in the MES test [113]. 


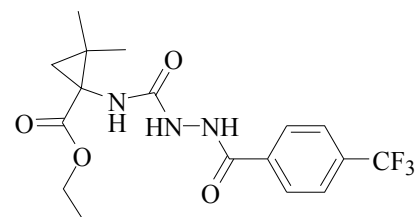

130

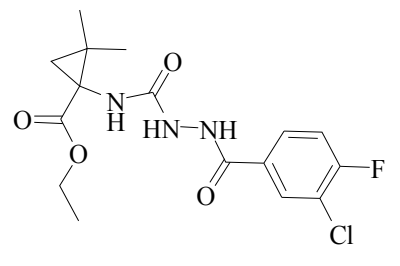

131

Figure 11. Structures of compounds 130-131.

\section{The Pyrrolidine-2,5-dione Functional Group}

Derivatives of pyrrolidine-2,5-diones, as heterocyclic compounds, have been widely applied in medicinal chemistry and synthesis fields. They exhibit numerous bioactivities, especially in anticonvulsant and tyrosinase inhibitory activities. Therefore, development of new and efficient strategies for the synthesis of multi-substituted pyrrolidine-2,5-diones is also the current hot in organic and medical chemistry [114].

Obniska et al., designed and synthesized many series pyrrolidine-2,5-diones (Table 7) and tested their anticonvulsant activity in the MES and metrazole seizure threshold (sc-Met) tests [115-127]. The quantitative evaluation in the MES seizures after oral administration into rats showed that the most active were compound 153 with $\mathrm{ED}_{50}$ of $7.4 \mathrm{mg} / \mathrm{kg}$ and compound 154 with $\mathrm{ED}_{50}$ of $26.4 \mathrm{mg} / \mathrm{kg}$. These molecules were more potent and also less neuron-toxicity than that of phenytoin which was used as reference antiepileptic drug. Although Kaminski et al., had reported several series pyrrolidine-2,5-diones (Table 7) used for anticonvulsant activity, none exhibited better than compound 153 [128-132].

Table 7. Structures of compounds 132-165.

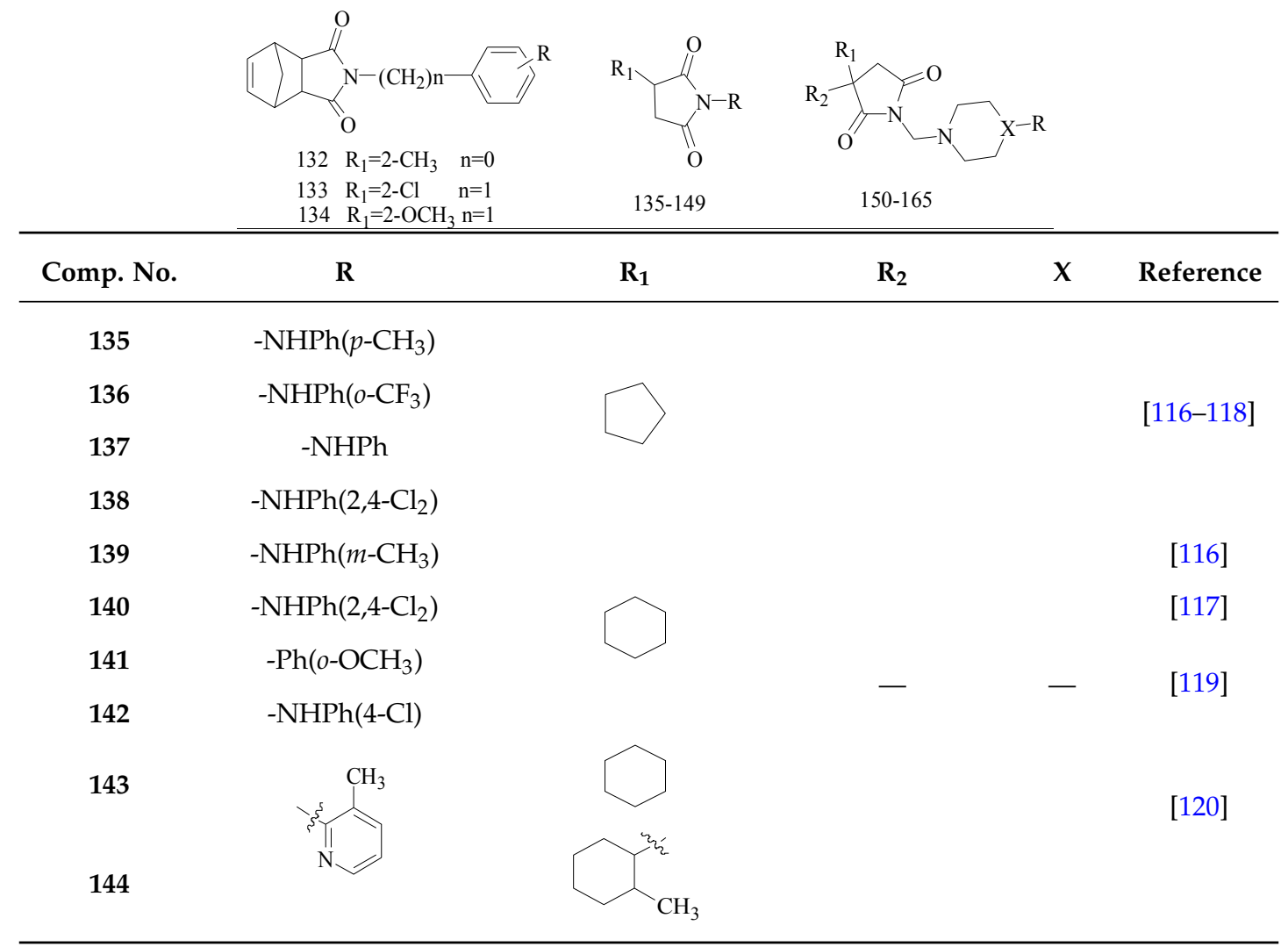


Table 7. Cont.

\begin{tabular}{|c|c|c|c|c|c|}
\hline Comp. No. & $\mathbf{R}$ & $\mathbf{R}_{1}$ & $\mathbf{R}_{2}$ & $x$ & Reference \\
\hline 145 & -NHPh & $\mathrm{H}_{3} \mathrm{C}_{\mathrm{CH}_{3}}$ & & & [121] \\
\hline 146 & & & & & [122] \\
\hline 147 & 7 & $-\mathrm{Ph}\left(o-\mathrm{CF}_{3}\right)$ & & & [123] \\
\hline 148 & $-\mathrm{N}\left(\mathrm{C}_{2} \mathrm{H}_{4}\right)_{2} \mathrm{~N}-\mathrm{CH}_{3}$ & $-\mathrm{Ph}(m-\mathrm{Cl})$ & & & [124] \\
\hline 149 & $\mathrm{O}$ & & & & [125] \\
\hline 150 & $-\mathrm{Ph}\left(m-\mathrm{CF}_{3}\right)$ & $-\mathrm{H}$ & $-\mathrm{Ph}\left(m-\mathrm{CH}_{3}\right)$ & \multirow{6}{*}{$\mathrm{N}$} & \multirow{5}{*}{ [126-128] } \\
\hline 151 & $-\mathrm{Ph}(p-\mathrm{Cl})$ & $-\mathrm{H}$ & $-\mathrm{Ph}(m-\mathrm{Cl})$ & & \\
\hline 152 & $-\mathrm{Ph}\left(m-\mathrm{CF}_{3}\right)$ & $-\mathrm{H}$ & $-\mathrm{Ph}(m-\mathrm{Cl})$ & & \\
\hline 153 & $-\mathrm{Ph}(p-\mathrm{F})$ & $-\mathrm{H}$ & $-\mathrm{Ph}(o-\mathrm{Br})$ & & \\
\hline 154 & $-\mathrm{Ph}(m-\mathrm{Cl})$ & $-\mathrm{H}$ & $-\mathrm{Ph}(o-\mathrm{Br})$ & & \\
\hline 155 & $-\mathrm{Ph}$ & $-\mathrm{H}$ & $-\mathrm{Ph}\left(m-\mathrm{CF}_{3}\right)$ & & \multirow[t]{2}{*}{ [123-128] } \\
\hline 156 & $-\mathrm{CH}_{2} \mathrm{Ph}$ & $-\mathrm{H}$ & $-\mathrm{Ph}(o-\mathrm{Cl})$ & C & \\
\hline 157 & - & $-\mathrm{H}$ & & $\mathrm{O}$ & [129] \\
\hline 158 & $-\mathrm{CH}_{2} \mathrm{CH}_{2} \mathrm{OH}$ & & & $\mathrm{N}$ & \multirow{2}{*}{ [130] } \\
\hline 159 & $-\mathrm{CH}_{2} \mathrm{Ph}$ & & $-\mathrm{Ph}$ & C & \\
\hline 160 & $-\mathrm{Ph}(p-\mathrm{F})$ & $-\mathrm{CH}_{3}$ & -111 & & \multirow{3}{*}{ [131] } \\
\hline 161 & $-\mathrm{Ph}(m-\mathrm{Cl})$ & & & & \\
\hline 162 & $-\mathrm{Ph}\left(3,4-\mathrm{Cl}_{2}\right)$ & & & $\mathrm{N}$ & \\
\hline 163 & $-\mathrm{Ph}\left(m-\mathrm{CF}_{3}\right)$ & $-\mathrm{Ph}$ & $-\mathrm{Ph}$ & & [132] \\
\hline 164 & $-\mathrm{Ph}\left(3,4-\mathrm{Cl}_{2}\right)$ & $-\mathrm{H}$ & $-\mathrm{CH}_{3}$ & & \multirow{2}{*}{ [133] } \\
\hline 165 & $-\mathrm{Ph}\left(3,4-\mathrm{Cl}_{2}\right)$ & $-\mathrm{H}$ & $-\mathrm{H}$ & & \\
\hline
\end{tabular}

Rybka et al., reported a synthesis of 22 new $N$-[(4-phenylpiperazin-1-yl)-methyl]-3-methylpyrrolidine-2,5-dione and pyrrolidine-2,5-dione derivatives. Administration to mice revealed that the most active compounds were compound 164 with $\mathrm{ED}_{50}=16.13 \mathrm{mg} / \mathrm{kg}(\mathrm{MES}), \mathrm{ED}_{50}=133.99 \mathrm{mg} / \mathrm{kg}$ (sc-PTZ) and compound 165 with ED $50=37.79 \mathrm{mg} / \mathrm{kg}$ (MES), $\mathrm{ED}_{50}=128.82 \mathrm{mg} / \mathrm{kg}$ (sc-PTZ) (Table 7). Compared with the positive control drugs valproate and ethosuximide, these compounds exhibited more activity and less neurotoxicity [133].

\section{The Imidazoline-2,4-dione Functional Group}

Imidazoline-2,4-diones, also called hydantoins, a class of cyclic imides, have been demonstrated to possess good anticonvulsant properties [134]. Their substitution products have also been found a number of other pharmacological properties such as antitumor, anti-HIV and antibacterial activities [135-137].

He et al., synthesized new 6-methyl-1-substituted-4,6-diazaspiro[2.4]heptane-5,7-diones and tested the anticonvulsant activity using the MES and sc-PTZ screens. Their neurotoxicity was 
determined by the rotarod test. The most active of the series was compound 166 (Table 8), which showed a MES ED 50 value of $12.5 \mathrm{mg} / \mathrm{kg}$ in mice. The $\mathrm{TD}_{50}$ was $310 \mathrm{mg} / \mathrm{kg}$, providing compound 166 with a PI of 24.8 in the MES test which is better than that of Phenytoin [138].

He et al., investigated some new N-3-arylamide substituted 5,5-cyclopropanespirohydantoin derivatives synthesized and tested for anticonvulsant activity using the maximal electroshock (MES), subcutaneous pentylenetetrazole (sc-PTZ) screens, which are the most widely employed seizure models for early identification of candidate anticonvulsants. Their neurotoxicity was determined applying the rotorod test. The most active compound 167 showed the MES-induced seizures with $\mathrm{ED}_{50}$ value of $9.2 \mathrm{mg} / \mathrm{kg}$ and $\mathrm{TD}_{50}$ value of $421.6 \mathrm{mg} / \mathrm{kg}$ after i.p. to mice (Table 8), which provided compound 167 with a protective index $\left(\mathrm{TD}_{50} / \mathrm{ED}_{50}\right)$ of 45.8 in the MES test [139].

Botros et al., designed and synthesized new phenytoin derivatives and tested the anticonvulsant activity. Preliminary anticonvulsant screening was performed using standard MES and sc-PTZ screens in mice. The neurotoxicity was determined by applying the rotarod test. Among these compounds, 168 and 169 showed the highest protection (80\%) in the sc-PTZ test at a dose of $100 \mathrm{mg} / \mathrm{kg}$, whereas the compound $\mathbf{1 7 0}$ displayed promising anticonvulsant effect in the MES model (Table 8) [140].

Byrtus et al., prepared a various of N-Mannich bases derived from 5-cyclopropyl-5-phenyland 5-cyclopropyl-5-(4-chlorophenyl)-imidazolidine-2,4-diones. The quantitative evaluation after oral administration in rats showed that the most active was compound $\mathbf{1 7 1}$ with $\mathrm{ED}_{50}$ values of $5.76 \mathrm{mg} / \mathrm{kg}$ (MES) and $57.31 \mathrm{mg} / \mathrm{kg}$ (sc-PTZ) (Table 8). Compared with the control drugs of ethosuximide and phenytoin, it was more active in the anti-convulsion assays. Additionally compound 171 with $\mathrm{ED}_{50}$ of $26.06 \mathrm{mg} / \mathrm{kg}$ in a psychomotor seizure test $(6-\mathrm{Hz})$ in mice showed comparable activity to a new generation anticonvulsant-levetiracetam [141].

Dhanawat et al., had reported a synthesis of $N$-(3)-substituted-2,4-imidazolidine diones and oxazolidinediones derivatives and tested the anticonvulsant activity using the MES test. Compounds 172, 173, 174 and 175 exhibited significant anticonvulsant activity as compared to the standard drug phenytoin (Table 8) [142].

Botros et al., described new bivalent ligands derived from phenytoin. Initial anticonvulsant screening was performed using MES and PTZ screens in mice. Most of the test compounds were found to be effective in at least one seizure model at a dose of $100 \mathrm{mg} / \mathrm{kg}$. Compound $\mathbf{1 7 6}$ exhibited marked anticonvulsant activity in both MES and PTZ screens (Table 8) [143].

Byrtus et al., established a synthesis of N-Mannich from 5-cyclopropyl-5-phenyl- and 5-cyclopropyl-5-(4-chlorophenyl)-hydantoins and tested their anticonvulsant activity. The quantitative studies after oral administration to rats showed that several molecules were more potent than phenytoin and ethosuximide which were used as reference antiepileptic drugs. From the whole series, the most active was compound 177 with the $\mathrm{ED}_{50}$ value of $5.29 \mathrm{mg} / \mathrm{kg}$ in the MES test (Table 8) [144].

Madaiah et al., demonstrated a synthesis of new 3-[(2,4-dioxo-1,3,8-triazaspiro[4,6]undec-3-yl) methyl]benzonitrile derivatives and evaluated their possible anticonvulsant activity by MES and PTZ tests. Compounds 178, 179, 180 and 181 showed significant and protective effect on seizure when compared with the standard drug valproate (Table 8). These compounds were found to exhibit advanced anticonvulsant activity as well as lower neurotoxicity than the reference drug [145].

Madaiah et al., synthesized a series of novel $1^{\prime}$-[2-(difluoromethoxy)benzyl]-2' $H, 5^{\prime} H$ spiro[8-azabicyclo[3,2,1] octane-3,4'-imidazolidine]-2',5'-dione substituted hydantoins. The novel molecules were screened for anticonvulsant activity in mice by MES and sc-PTZ-induced seizure tests. The neurotoxicity was assessed using the rotarod method. Compounds 182, 183, 184, 185 and 186 exhibited anticonvulsant potency against MES-induced seizure and in the sc-PTZ model (Table 8), with lesser neurotoxicity. Some title compounds showed lesser depression on central nervous system compared to phenytoin [146]. 
Table 8. Structures of compounds 166-186.

\begin{tabular}{|c|c|c|c|c|}
\hline $\begin{array}{l}\mathrm{R}_{2} \\
\mathrm{R}_{1}\end{array}$ & 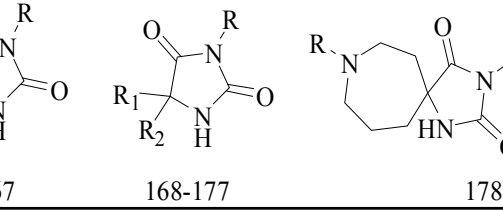 & & $\begin{array}{l}\mathrm{N} \\
\mathrm{H}\end{array}$ & \\
\hline Comp. No. & $\mathbf{R}$ & $\mathbf{R}_{\mathbf{1}}$ & $\mathbf{R}_{\mathbf{2}}$ & Reference \\
\hline 166 & $-\mathrm{CH}_{3}$ & $\mathrm{H}$ & $-\mathrm{Ph}\left(\mathrm{p}-\mathrm{SO}_{2} \mathrm{CH}_{3}\right)$ & [138] \\
\hline 167 & $-\mathrm{NHCOPh}\left(p-\mathrm{CF}_{3}\right)$ & $-\mathrm{CH}_{3}$ & $-\mathrm{CH}_{3}$ & [139] \\
\hline 168 & $-\mathrm{CH}_{2} \mathrm{C}(\mathrm{O}) \mathrm{NNCSH}$ & $-\mathrm{Ph}$ & $-\mathrm{Ph}$ & \\
\hline 169 & $-\mathrm{CH}_{2} \mathrm{CONHNHCSNHPh}\left(\mathrm{p}-\mathrm{OCH}_{3}\right)$ & $-\mathrm{Ph}$ & $-\mathrm{Ph}$ & {$[140]$} \\
\hline 170 & $-\mathrm{CH}_{2} \mathrm{CONHNHCSNHPh}$ & $-\mathrm{Ph}$ & $-\mathrm{Ph}$ & \\
\hline 171 & $-\mathrm{H}$ & $-\mathrm{Ph}$ & $-\mathrm{C}_{3} \mathrm{H}_{5}$ & [141] \\
\hline 172 & $-\mathrm{CH}_{2} \mathrm{~N}\left(\mathrm{CH}_{2} \mathrm{CH}_{2}\right)_{2} \mathrm{Ph}$ & $-\mathrm{Ph}$ & $-\mathrm{C}_{3} \mathrm{H}_{5}$ & \\
\hline 173 & $-\mathrm{CH}_{2} \mathrm{CONHPh}(p-\mathrm{Cl})$ & $-\mathrm{Ph}$ & $-\mathrm{Ph}$ & \\
\hline 174 & $-\mathrm{CH}_{2} \mathrm{CONHPh}(o-\mathrm{Cl})$ & $-\mathrm{Ph}$ & $-\mathrm{Ph}$ & {$[142]$} \\
\hline 175 & $-\mathrm{CH}_{2} \mathrm{CONHPh}\left(p-\mathrm{OCH}_{3}\right)$ & $-\mathrm{Ph}$ & $-\mathrm{Ph}$ & \\
\hline 176 & $-\mathrm{CH}_{2} \mathrm{CON}\left(\mathrm{CH}_{2} \mathrm{CH}_{2}\right)_{2} \mathrm{Ph}\left(p-\mathrm{NO}_{2}\right)$ & $-\mathrm{Ph}$ & $-\mathrm{Ph}$ & [143] \\
\hline 177 & $\begin{array}{c}-\left(\mathrm{CH}_{2}\right)_{2} \mathrm{O}\left(\mathrm{CH}_{2}\right)_{2} \\
\mathrm{~N}\left(\mathrm{CH}_{2} \mathrm{CH}_{2}\right)_{2} \mathrm{Ph}(p-\mathrm{Cl})\end{array}$ & $-\mathrm{Ph}$ & $-\mathrm{Ph}$ & [144] \\
\hline 178 & $-\mathrm{SO}_{2} \mathrm{Ph}(o-\mathrm{F})$ & & & \\
\hline 179 & $-\mathrm{SO}_{2} \mathrm{Ph}(m-\mathrm{F})$ & & & {$[145]$} \\
\hline 180 & $-\mathrm{CO} \mathrm{Ph}(m-\mathrm{F})$ & & & [145] \\
\hline 181 & $-\mathrm{CO} \mathrm{Ph}(p-\mathrm{F})$ & & & \\
\hline 182 & $-\mathrm{SO}_{2} \mathrm{Ph}(o-\mathrm{F})$ & - & - & \\
\hline 183 & $-\mathrm{SO}_{2} \mathrm{Ph}(m-\mathrm{F})$ & & & \\
\hline 184 & $-\mathrm{SO}_{2} \mathrm{Ph}(o-\mathrm{F})$ & & & [146] \\
\hline 185 & $-\mathrm{CONHPh}$ & & & \\
\hline 186 & $-\mathrm{CONHPh}\left(m-\mathrm{CH}_{3}\right)$ & & & \\
\hline
\end{tabular}

\section{The Oxime Ether Functional Group}

Due to the lipophilic aryl portion facilitating penetration of the blood-brain barrier, the introduction of oxime ether groups to the compounds as a small oxygen functional group had been studied. Meanwhile, oxime ether linkages also are used as a mechanism for pro-drug generation [147].

Karakurt et al., prepared oxime and oxime ether derivatives of anticonvulsant nafimidone [1-(2-naphthyl)-2-(imidozole-1-yl)ethanone] as potential anticonvulsant compounds. Most of the compounds exhibited anticonvulsant activities. Compounds 187, 188 and 189 (salt) were found to be active at $30 \mathrm{mg} / \mathrm{kg}$ at the half-hour time point without neurotoxicity at the same dose level (Table 9). Meanwhile, these derivatives exhibited some activity against sc-Met as well as MES-induced seizures [148].

Karakurt et al., reported synthesis of twenty-three new oxime ester derivatives of nafimidone. MES and sc-Met tests were employed for their anticonvulsant activities and rotarod test for neurological deficits. Compound $\mathbf{1 9 0}$ was the most active one in sc-Met test at all dose levels at $4 \mathrm{~h}$ (Table 9) [149].

Bansal et al., synthesized O-alkylated derivatives of 1-(2-naphthyl)-2-(imidazol-1-yl)ethanone oxime as potential anticonvulsant compounds. Pre-treatment of mice with compounds 191 and 192 (30 mg/kg, i.p.) significantly decreased the susceptibility to PTZ-induced seizure as evidenced by delayed onset of clonus and mean onset time of extensor phase (Table 8). The treatment of mice with these compounds show equivalent protection level as compared with standard drug diazepam ( $0.5 \mathrm{mg} / \mathrm{kg}$, i.p.). Anticonvulsant evaluation data showed that compounds 191 and 192 were the most active with $\mathrm{ED}_{50}$ values of $46.77 \mathrm{mg} / \mathrm{kg}$ and $24.41 \mathrm{mg} / \mathrm{kg}$, respectively [150]. 
Karakurt et al., synthesized oxime and oxime ether derivatives of [1-(2-naphthyl)-2(1,2,4-triazol-1-yl)ethanone] as potential anticonvulsant compounds. The most active of the series was compound 193 (Table 8) [151].

Table 9. Structures of compounds 187-193.

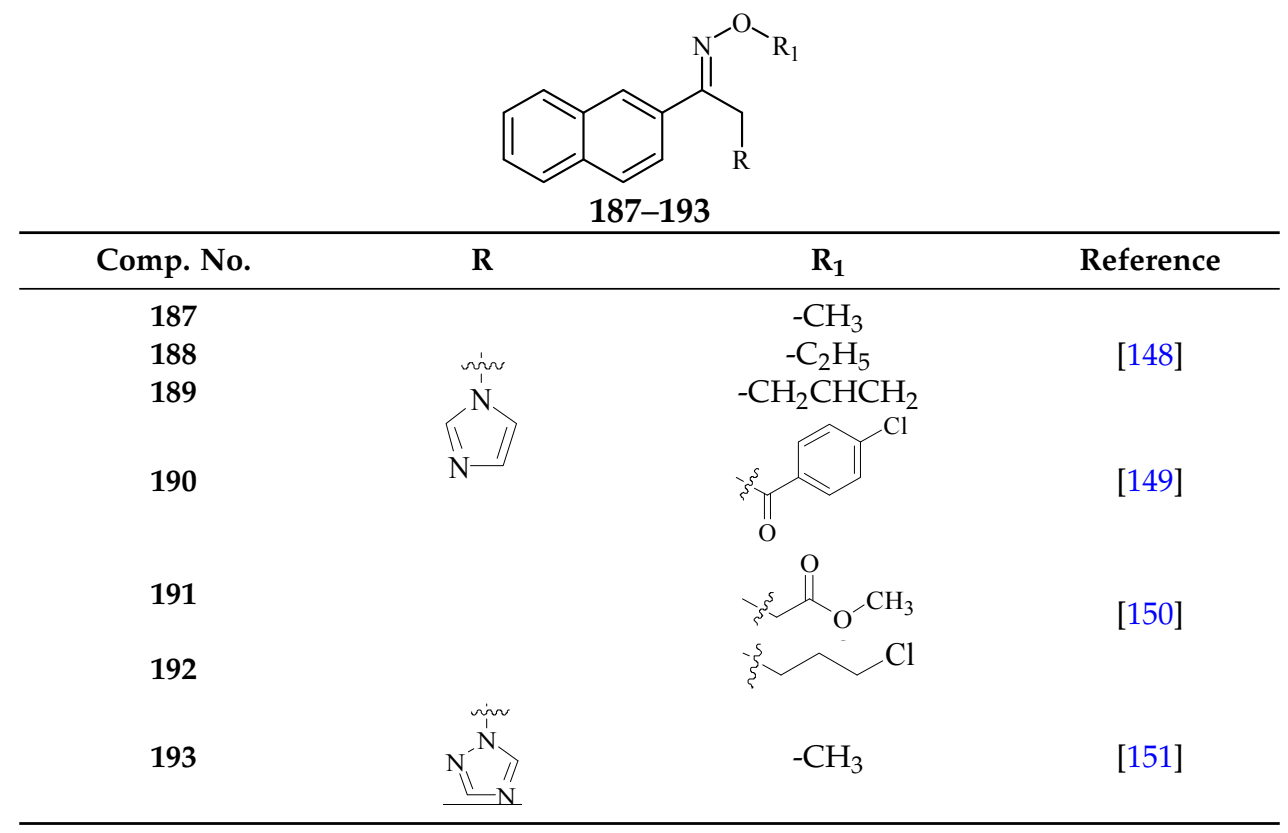

\section{The Pyridazine Functional Group}

Pyridazine is a heterocyclic organic compound with the molecular formula $(\mathrm{CH})_{4} \mathrm{~N}_{2}$. It contains a six-membered ring with two adjacent nitrogen atoms, and is aromatic [150]. Pyridazine derivatives have various biological applications [152-155].

Guan et al., synthesized a series of 6-alkoxy-[1,2,4]triazolo[4,3-b]pyridazine derivatives. In initial screening and quantitative evaluation, compound 194 was the most active agent, exhibiting the lowest toxicity at the same time (Table 10). In the anti-MES test, it showed $\mathrm{ED}_{50}$ of $17.3 \mathrm{mg} / \mathrm{kg}$ and $\mathrm{TD}_{50}$ of $380.3 \mathrm{mg} / \mathrm{kg}$, and the PI of 22.0 which is much better than PI of the reference drugs [156].

Table 10. Structures of compounds 194-200.

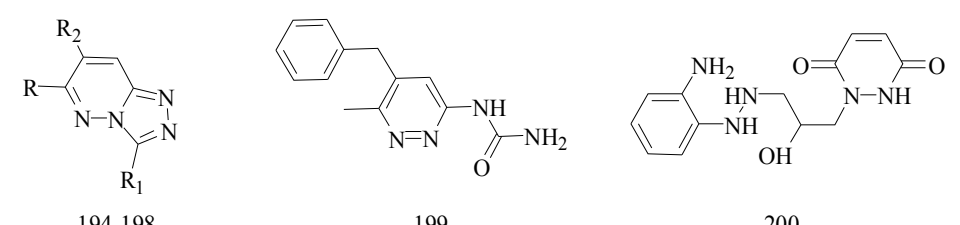

\begin{tabular}{ccccc}
\multicolumn{2}{c}{$194-198$} & \multicolumn{2}{c}{200} \\
\hline Comp. No. & $\mathbf{R}$ & $\mathbf{R}_{\mathbf{1}}$ & $\mathbf{R}_{\mathbf{2}}$ & Reference \\
\hline $\mathbf{1 9 4}$ & $-\mathrm{OPh}\left(2,4-\mathrm{Cl}_{2}\right)$ & $\mathrm{H}$ & $\mathrm{H}$ & {$[156]$} \\
$\mathbf{1 9 5}$ & $-\mathrm{CH}_{3}$ & $\mathrm{H}$ & $-\mathrm{CH}_{2} \mathrm{Ph}$ & {$[157]$} \\
$\mathbf{1 9 6}$ & $-\mathrm{CH}_{3}$ & $\mathrm{H}$ & $-\mathrm{CH}_{2} \mathrm{Ph}\left(2,6-\mathrm{Cl}_{2}\right)$ & \\
$\mathbf{1 9 7}$ & $-\mathrm{CH}_{3}$ & $-\mathrm{NH}_{2}$ & $-\mathrm{CH}_{2} \mathrm{Ph}$ & {$[158]$} \\
$\mathbf{1 9 8}$ & $-\mathrm{CH}_{3}$ & $-\mathrm{NH}_{2}$ & $-\mathrm{CH}_{2} \mathrm{Ph}\left(2,6-\mathrm{Cl}_{2}\right)$ & \\
\hline
\end{tabular}

Sivakumar et al., reported synthesis of 1-substituted-1,2-dihydro-pyridazine-3,6-diones as potential anticonvulsant agents. The compounds were tested in vivo for the anticonvulsant activity. The compound which have maximum protection against MES-induced seizures was compound 195 with $\mathrm{ED}_{50}=44.7 \mathrm{mg} / \mathrm{kg}$ i.p. $4 \mathrm{~h}$ (Table 10) [157]. 
Moreau et al., reported a synthesis of several 3-substituted pyridazines and a series of imidazo- and triazolopyridazines and tested their anticonvulsant activity against MES-induced seizures in mice. The most active derivatives, 196, 197, 198, 199 and 200 with oral $\mathrm{ED}_{50}$ ranged from 6.2 to $22.0 \mathrm{mg} / \mathrm{kg}$ (Table 10). The compound 200 was also protective in the PTZ-induced seizure test $\left(\mathrm{ED}_{50}=76 \mathrm{mg} / \mathrm{kg}\right.$ per os $)$ and blocked strychnine-induced tonic extensor seizures $\left(E_{50}=34.5 \mathrm{mg} / \mathrm{kg}\right.$ per os). Furthermore, derivative 200 showed anticonvulsant effects on bicuculline- and yohimbine-induced seizure tests in mice [158].

\section{Miscellaneous Functional Groups}

Sapa et al., established a synthesis of some novel pyrrolidin-2-one derivatives and evaluated their possible anticonvulsant activity by MES and PTZ tests. Compound 201 significantly reduced the incidence of seizures in the MES test. The compounds 202 and 203 demonstrated activity in the PTZ-induced seizures test $[159,160]$.

Nevagi et al., demonstrated synthesis of novel thiosemicarbazide derivatives and evaluated their anticonvulsant activity and neurotoxicity. Amongst all the synthesized compounds, compound 204 is a broad-spectrum anticonvulsant agent since it was active in both MES- and PTZ-induced seizure models with no neurotoxicity (Figure 12) [161].

Dawidowski et al., synthesized a series of novel diastereomerically pure, monocyclic 2,6-DKP derivatives using a diastereoselective method. In the MES test, some of them showed good or weak antiepileptic activities, however, there was no active compound in the sc-Met screen. The most promising compound 205 exhibited notable action in the $6 \mathrm{~Hz}$ test (Figure 12) [162].

Strupińska et al., synthesized a series of benzylamides of isocyclic and heterocyclic acids and tested their anticonvulsant activity. Nearly all synthesized heterocyclic acid derivatives showed anticonvulsant activity. Compound 206 appeared the most promising (Figure 12). It showed in minimal clonic seizure $(6 \mathrm{~Hz})$ test (ASP) in rats after i.p. administration: $\mathrm{MES} \mathrm{ED}_{50}=36.5 \mathrm{mg} / \mathrm{kg}$, TOX $\mathrm{TD}_{50}=269.75 \mathrm{mg} / \mathrm{kg}$, and PI $=7.39$ [163].

Pastore et al., synthesized novel $N$-derivative-1,2,3-oxathia-zolidine-4-one-2,2-dioxides heterocycles, bioisosteres of trimethadione (TMD, oxazolidine-2,4-dione) and phenytoin. Anticonvulsant screening was performed in mice after intraperitoneal administration in the MES test and sc-PTZ test. Compound 207 (Figure 12), the most active drug obtained, with an $\mathrm{ED}_{50}$ of $60 \mu \mathrm{g} / \mathrm{kg}$ was 10,000 times more active than TMD, the reference compound in this work, and 90 times more active than valproic acid, an anticonvulsant drug presently in use in the clinic [164].

Uysal et al., designed and synthesized sixteen 2/3-benzoylaminopropionanilide derivatives. The anticonvulsant activity profile of the synthesized compounds was determined by MES and sc-Met seizure tests. In the rotarod test, all of them exhibited no toxicity to the nervous system. Compounds 208, 209 and 210 were found to be more potent in the MES or sc-Met tests (Figure 12). Those compounds have emerged as lead compounds for future investigations [165].

Guan et al., prepared a variety of $N$-(2-hydroxyethyl)cinnamamide derivatives and screened their anticonvulsant activities by the MES test and their neurotoxicity was evaluated by the rotarod test. In the anti-MES potency test, compounds 211 and 212 exhibited $\mathrm{ED}_{50}$ dose of 17.7 and $17.0 \mathrm{mg} / \mathrm{kg}$, respectively (Figure 12), and $\mathrm{TD}_{50}$ dose of 154.9 and $211.1 \mathrm{mg} / \mathrm{kg}$, respectively, resulting in a PI of 8.8 and 12.4, respectively, which were much greater than the PI of the market antiepileptic drug carbamazepine [166].

Alswah et al., reported synthesis of some [1,2,4]triazolo[4,3-a]quinoxaline derivatives as novel anticonvulsant agents. The anticonvulsant evaluation was used metrazol-induced convulsion model and phenobarbitone sodium was as a standard. Among this set of tested compounds, two of them (213 and 214) showed the best anticonvulsant activities (Figure 12) [167].

Chen et al., reported synthesis of 4-(4-alkoxylphenyl)-3-ethyl-4H-1,2,4-triazole derivatives. Their anticonvulsant activities were evaluated by the MES test and their neurotoxicity was evaluated by the rotarod test. MES test showed that compound 215 was found to be the most potent with $\mathrm{ED}_{50}$ 
value of $8.3 \mathrm{mg} / \mathrm{kg}$ and PI value of 5.5, but compound 216 exhibited better PI value of 9.3 (Figure 12), which was much greater than PI value of the prototype drug phenytoin [168].
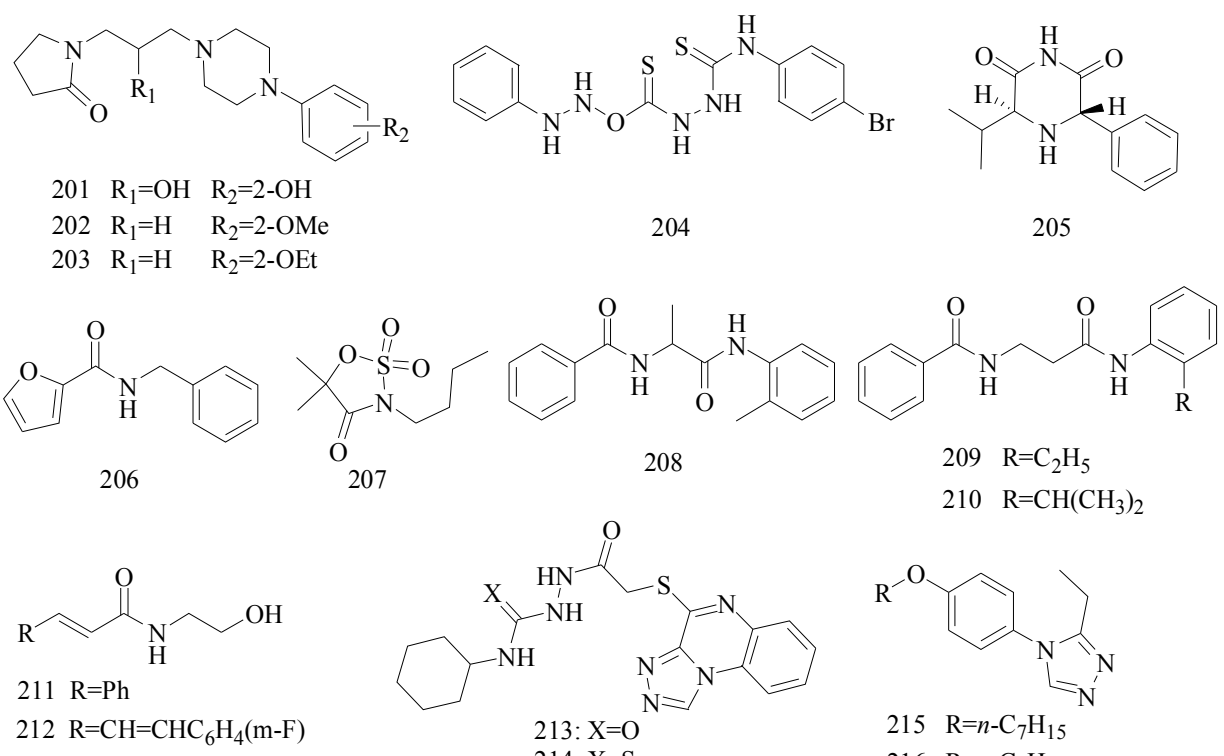

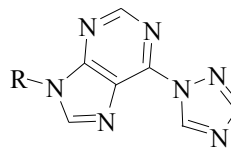

$217 \mathrm{R}=n-\mathrm{C}_{10} \mathrm{H}_{21}$

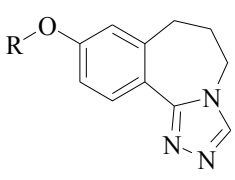

$\begin{array}{ll}221 & \mathrm{R}=n-\mathrm{C}_{6} \mathrm{H}_{13} \\ 222 & \mathrm{R}=n-\mathrm{C}_{5} \mathrm{H}_{11}\end{array}$

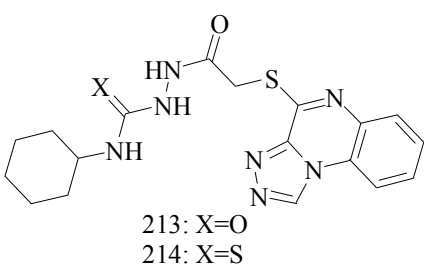

$\mathrm{Cl}$

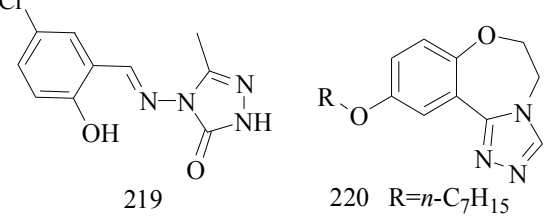

218
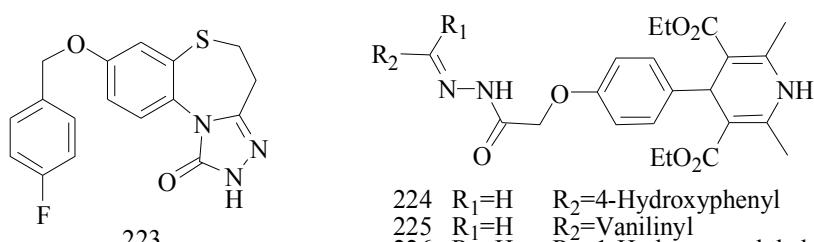

$224 \mathrm{R}_{1}=\mathrm{H} \quad \mathrm{R}_{2}=4$-Hydroxyphenyl

$225 \quad \mathrm{R}_{1}=\mathrm{H} \quad \mathrm{R}_{2}=$ Vaniliny

$226 \quad \mathrm{R}_{1}=\mathrm{H} \quad \mathrm{R}_{2}=1$-Hydroxy-naphthalein-2-yl

$227 \mathrm{R}_{1}=\mathrm{CH}_{3} \quad \mathrm{R}_{2}=4$-Fluorophenyl

Figure 12. Structures of compounds 201-227.

Wang et al., synthesized a series of new purines containing triazole and other heterocycle substituents and evaluated their preliminary anticonvulsant activity and neurotoxicity by using the MES, sc-PTZ and rotarod tests. Among the compounds studied, compound 217 was the most potent compound, with a $\mathrm{ED}_{50}$ of $23.4 \mathrm{mg} / \mathrm{kg}$ and a high protective index of more than 25.6 after intraperitoneal administration in mice (Figure 12). Compound 217 showed significant oral activity against MES-induced seizures in mice, with an $\mathrm{ED}_{50}$ of $39.4 \mathrm{mg} / \mathrm{kg}$ and a PI above 31.6 [169].

Shu et al., reported synthesis of 4-(3-alkoxy-phenyl)-2,4-dihydro-[1,2,4]triazol-3-ones. All target compounds exhibited anticonvulsant activity of varying degrees in the maximal electroshock test. Compound 218 was the most promising compound with an $\mathrm{ED}_{50}$ value of $30.5 \mathrm{mg} / \mathrm{kg}$ and a PI of 18.63 (Figure 12), showing a higher safety than the standard drug carbamazepine (PI $=6.45$ ). In addition, the potency of compound 218 against seizures induced by pentylenetetrazole and 3-mercaptopropionic acid suggested its broad-spectrum activity [170].

Kahveci et al., designed and synthesized a series of new 1,2,4-triazole-3-one derivatives bearing the salicyl moiety. The anticonvulsant activities of all compounds were evaluated by the Anticonvulsant Screening Program of the U.S. National Institutes of Health. The most active 
compound 219 showed significant anticonvulsant activity with an $\mathrm{ED}_{50}$ of $81.1 \mathrm{mg} / \mathrm{kg}$ at an approximate TPE (time of peak effect) of $1 \mathrm{~h}$ (Figure 12) [171].

Deng et al., reported a synthesis of 10-alkoxy-5,6-dihydrotriazolo[4,3- $d]$ benzo[f][1,4] oxazepine derivatives and screened their anticonvulsant activities by the MES test and their neurotoxicity was evaluated by the rotarod test. In the MES test, compound $\mathbf{2 2 0}$ was found to possess better anticonvulsant activity and higher safety than market drugs carbamazepine and phenytoin with an $\mathrm{ED}_{50}$ value of $6.9 \mathrm{mg} / \mathrm{kg}$ a PI value of 9.5 (Figure 12) [172].

Piao et al., reported a novel series of 9-alkoxy-6,7-dihydro-5H-benzo[c][1,2,4]triazolo[4,3-a] azepine derivatives and screened their anticonvulsant activity by the MES test and the sc-PTZ test. The results revealed that all of the compounds exhibited anticonvulsant activity, compound $\mathbf{2 2 1}$ was found to possess the most potent anticonvulsant activity in the anti-MES potency test (Figure 12), it had a $\mathrm{ED}_{50}$ value of $12.3 \mathrm{mg} / \mathrm{kg}$, a TD 50 value of $73.5 \mathrm{mg} / \mathrm{kg}$, and a PI of 6.0, which was slightly lower than the PI of the prototype drug carbamazepine $\left(\mathrm{ED}_{50}=8.8, \mathrm{PI}=8.1\right)$. In the $s c$-PTZ test, compound 222 was the most active, with an $\mathrm{ED}_{50}$ value of $19.8 \mathrm{mg} / \mathrm{kg}$, a $\mathrm{TD}_{50}$ value of $80.8 \mathrm{mg} / \mathrm{kg}$ and a PI value of 4.1, which are greatly higher than that of carbamazepine $\left(\mathrm{ED}_{50}>100, \mathrm{PI}<0.72\right)$ [173].

Deng et al., synthesized two series of 8-alkoxy-4,5-dihydrobenzo[b][1,2,4]triazolo[4,3- $d]$ $[1,4]$ thiazepine derivatives. All of the prepared compounds were effective in the MES screens, among which, compound 223 was considered as the most promising one with an $\mathrm{ED}_{50}$ value of $26.3 \mathrm{mg} / \mathrm{kg}$ and a superior PI value of 12.6 (Figure 12). The potency of compound 223 against seizures induced by pentylenetetrazole, 3-mercaptopropionic acid and bicuculline was great too [174].

Ulloora et al., synthesized new substituted 1,4-dihydropyridin-4-yl-phenoxyacetohydrazones. The final compounds were screened for their in vivo anticonvulsant activity by MES, sc-PTZ and $6 \mathrm{~Hz}$ methods. The active compounds, 224, 225, 226 and 227 exhibited their activities at $4 \mathrm{~h}$ after i.p. injection with $100 \mathrm{mg} / \mathrm{kg}$ (Figure 12). All these tested compounds exhibited activity in $6 \mathrm{~Hz}$ method within $1 \mathrm{~h}$ [175].

Siddiqui et al., reported synthesis of various 1-[6-(4-substituted phenyl)-3-cyano-4-(substituted phenyl)-pyridin-2-yl]-5-oxopyrrolidine-3-carboxylic acids. Their in vivo anticonvulsant evaluation was performed by MES and sc-PTZ tests. Compounds 228 and 229 displayed comparable anticonvulsant activity to the standard drugs with $\mathrm{ED}_{50}$ values of 13.4 and $18.6 \mathrm{mg} / \mathrm{kg}$ in electroshock screen, respectively (Figure 13). The compounds $\mathbf{2 2 8}$ and $\mathbf{2 2 9}$ were also found to have encouraging anticonvulsant activity ( $\mathrm{ED}_{50}=86.1$ and $271.6 \mathrm{mg} / \mathrm{kg}$, respectively) in sc-PTZ screen. Interestingly, they did not show any sign of motor impairment at the maximum dose administered and were not toxic to the liver [176].

Lee et al., prepared 13 derivatives of $N$-(biphenyl-4'-yl)methyl-(R)-2-acetamido-3-methoxypropionamide that were tested for anticonvulsant activity at the Anticonvulsant Screening Program (ASP) of the National Institute of Neurological Disorders and Stroke (NINDS) of the U.S. National Institutes of Health. The excellent activities in the MES test (mice, i.p.) of the compound 230 and $231\left(\mathrm{ED}_{50}=9.8\right.$ and $12 \mathrm{mg} / \mathrm{kg}$, respectively) coupled with their low neurotoxicities $\left(\mathrm{TD}_{50}=74\right.$ and $86 \mathrm{mg} / \mathrm{kg}$, respectively) provided compounds with notably higher PI (7.6 and 7.2, respectively) (Figure 13) [177].

Siddiqui et al., prepared a series of 4-thiazolidinones bearing a sulfonamide group and tested their anticonvulsant activity utilizing MES and sc-PTZ animal models. Compounds 232, 233 and $\mathbf{2 3 4}$ displayed promising activity and could be considered as leads for further investigations (Figure 13) [178].

Hen et al., synthesized a novel class of 19 carbamates and evaluated their anticonvulsant activity in the rat MES and $s c$-Met seizure tests and pilocarpine-induced status epilepticus (SE) model. The carbamates $235($ MES ED $50=64 \mathrm{mg} / \mathrm{kg}), 236\left(\mathrm{MES} \mathrm{ED}_{50}=52 \mathrm{mg} / \mathrm{kg}\right)$ and $237\left(\mathrm{MES} \mathrm{ED}_{50}=16 \mathrm{mg} / \mathrm{kg}\right)$ offered an optimal anticonvulsant efficacy and safety profile and consequently are potential candidates for further development as new AEDs (Figure 13) [179]. 
Hen et al., synthesized a novel class of aromatic amides composed of phenylacetic acid or branched aliphatic carboxylic acids, with five to nine carbons in their carboxylic moiety, and aminobenzenesulfonamide. The final compounds were screened for their anticonvulsant activity by MES and sc-Met tests. The amides 238, 239 and $\mathbf{2 4 0}$ were the most potent compounds possessing MES-ED 50 values of $7.6,9.9$, and $9.4 \mathrm{mg} / \mathrm{kg}$ and remarkable PI values of $65.7,50.5$, and 53.2, respectively (Figure 13) [180].
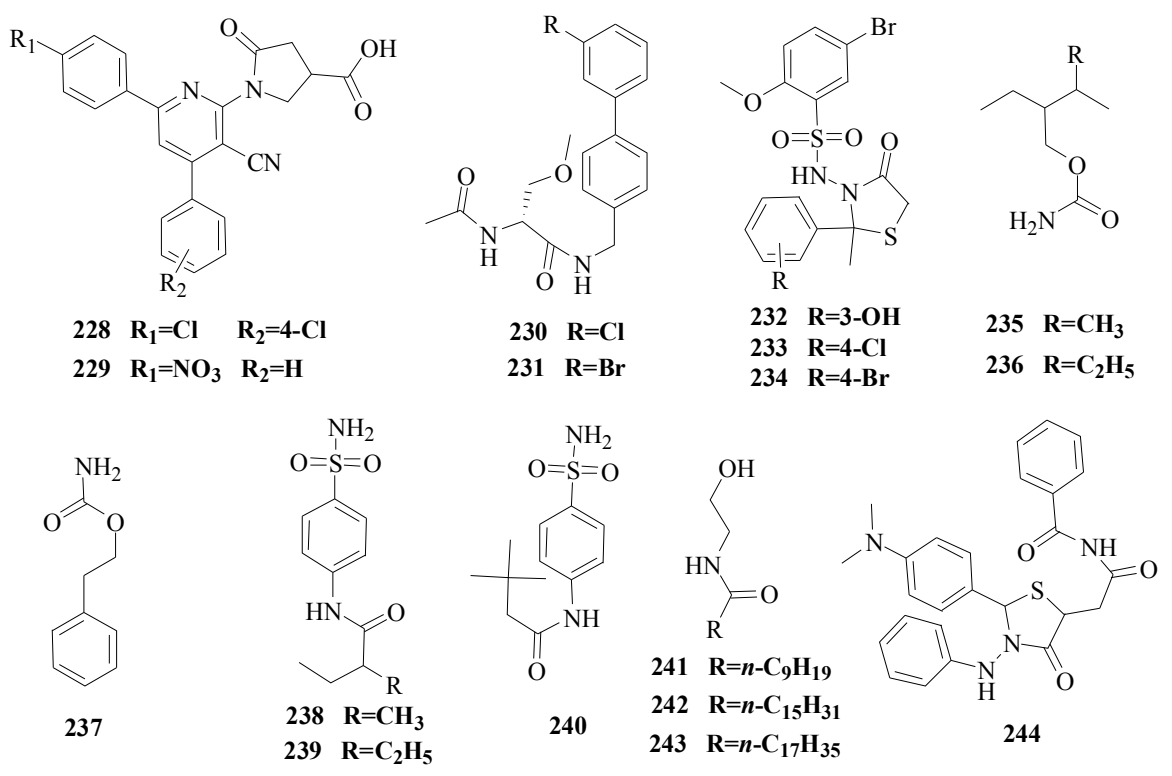

Figure 13. Structures of compounds 228-244.

Guan et al., demonstrated a synthesis of novel series of $N$-(2-hydroxyethyl)amide derivatives and screened their anticonvulsant activities by the MES test, and their neurotoxicity was evaluated by the rotarod test. The MES test showed that compounds 241, 242 and 243 were found to show a better anticonvulsant activity and also had lower toxicity than the market anti-epileptic drug valproate (Figure 13).

In the anti-MES potency test, these compounds exhibited $\mathrm{ED}_{50}$ doses of 22.0, 23.3, $20.5 \mathrm{mg} / \mathrm{kg}$, respectively, and $\mathrm{TD}_{50}$ doses of 599.8, $>1000,>1000 \mathrm{mg} / \mathrm{kg}$, respectively, resulting in a PI of 27.5, $>42.9,>48.8$, respectively, which are much higher than valproate $(\mathrm{PI}=1.6)$ [181].

Senthilraja et al., synthesized a new series of 2-(4-dimethylaminophenyl)-3-substituted thiazolidin-4-one-5-yl-acetyl acetamides/benzamides. The title compounds were investigated for their anticonvulsant activities, among the test compounds, compound 244 emerged as the most active compound of the series and as moderately more potent than the reference standard diazepam (Figure 13) [182].

\section{Conclusions}

All in all, based on our laboratory work and the recent literature, this review summarized some significant anticonvulsant compounds which are classified by functional groups and according to data obtained by studies designed in animal models. This review illustrates the various attempts made to discover and develop antiepileptic compounds with more effective and selective effects, and reduced secondary actions. The extensive work reviewed here may represent a starting point to allow a better understanding of antiepileptic therapeutic developments as well as to suggest ideas on design and synthesis of novel antiepileptic compounds. 
Acknowledgments: This work was support by Inner Mongolia Natural Science Foundation (No. 2012MS1165), project in Inner Mongolia autonomous region department of education (No. NJZC13444) and the doctoral scientific research foundation of Inner Mongolia University for the Nationalities (No. BS290).

Author Contributions: Cheng-Xi Wei and Ming Bian did equal work on researching the literature and writing the paper. Yue-Hui Bai corrected the manuscript. Guo-Hua Gong directed the work and corrected the manuscript.

Conflicts of Interest: This work has been supported by Inner Mongolia University for the Nationalities of the Department of Pharmacology. The authors state no conflict of interest and have received no payment in preparation of this manuscript.

\section{References}

1. Beghi, E.; Hesdorffer, D. Prevalence of epilepsy-An unknown quantity. Epilepsy 2014, 55, $963-967$. [CrossRef] [PubMed]

2. Curia, G.; Lucchi, C.; Vinet, J.; Gualtieri, F.; Marinelli, C.; Torsello, A.; Costantino, L.; Biagini, G. Pathophysiogenesis of mesial temporal lobe epilepsy: Is prevention of damage antiepileptogenic? Curr. Med. Chem. 2014, 21, 663-688. [CrossRef] [PubMed]

3. Kwan, P.; Brodie, M.J. Early identification of refractory epilepsy. N. Engl. J. Med. 2000, 342, 314-319. [CrossRef] [PubMed]

4. Spear, B.B. Pharmacogenetics and antiepileptic drugs. Epilepsia 2001, 5, 31-34. [CrossRef]

5. Al-Soud, Y.A.; Al-Masoudi, N.A.; Ferwanah, A.-R. Synthesis and properties of new substituted 1,2,4-triazoles: Potential antitumor agents. Bioorg. Med. Chem. 2003, 11, 1701-1708. [CrossRef]

6. Dimmock, J.R.; Pandeya, S.N.; Quail, J.W.; Pugazhenthi, U.; Allen, T.M.; Kao, G.Y.; Balzarini, J.; DeClercq, E. Evaluation of the semicarbazones, thiosemicarbazones and bis-carbohydrazones of some aryl alicycylic ketones for anticonvulsant and other biological propertie. Eur. J. Med. Chem. 1995, 30, 303-314. [CrossRef]

7. Meador, K.J. Newer anticonvulsants: Dosing strategies and cognition in treating patients with mood disorders and epilepsy. J. Clin. Psychiatry 2003, 64, 30-34. [PubMed]

8. Belcastro, V.; Striano, P.; Gorgone, G.; Costa, C.; Ciampa, C.; Caccamo, D.; Pisani, L.R.; Oteri, G.; Marciani, M.G.; Aguglia, U.; et al. Hyperhomocysteinemia in epileptic patients on new antiepileptic drugs. Epilepsia 2010, 51, 274-279. [CrossRef] [PubMed]

9. Bootsma, H.P.; Ricker, L.; Hekster, Y.A.; Hulsman, J.; Lambrechts, D.; Majoie, M.; Schellekens, A.; de Krom, M.; Aldenkamp, A.P. The impact of side effects on long-term retention in three new antiepileptic drugs. Seizure 2009, 18, 327-331. [CrossRef] [PubMed]

10. Kennedy, G.M.; Lhatoo, S.D. CNS adverse events associated with antiepileptic drugs. CNS Drugs 2008, 22, 739-760. [CrossRef] [PubMed]

11. Penovich, P.E.; Willmore, L.J. Use of a new antiepileptic drug or an old one as first drug for treatment of absence epilepsy. Epilepsia 2009, 50, 37-41. [CrossRef] [PubMed]

12. Xie, Z.F.; Chai, K.Y.; Piao, H.R.; Kwak, K.C.; Quan, Z.S. Synthesis and anticonvulsant activity of 7-alkoxyl-4,5-dihydro-[1,2,4]triazolo[4,3-a]quinolines. Bioorg. Med. Chem. Lett. 2005, 15, 4803-4805. [CrossRef] [PubMed]

13. Cui, L.J.; Xie, Z.F.; Piao, H.R.; Li, G.; Chai, K.Y.; Quan, Z.S. Synthesis and anticonvulsant activity of 1-substituted-7-benzyloxy-4,5-dihydro-[1,2,4]triazolo[4,3-a]quinoline. Biol. Pharm. Bull. 2005, 28, 1216-1220. [CrossRef] [PubMed]

14. Jin, H.G.; Sun, X.Y.; Chai, K.Y.; Piao, H.R.; Quan, Z.S. Anticonvulsant and toxicity evaluation of some 7-alkoxy-4,5-dihydro-[1,2,4]triazolo[4,3-a]quinoline-1(2H)-ones. Bioorg. Med. Chem. 2006, 14, 6868-6873. [CrossRef] [PubMed]

15. Sun, X.Y.; Jin, Y.Z.; Li, F.N.; Li, G.; Chai, K.Y.; Quan, Z.S. Synthesis of 8-alkoxy-4,5-dihydro-[1,2,4]triazole quinoline-1-ones and evaluation of their anticonvulsant properties. Arch. Pharm. Res. 2006, 29, 1080-1085. [CrossRef] [PubMed]

16. Wei, C.X.; Li, F.N.; Zhao, L.X.; Zhao, L.M.; Quan, Z.S. Synthesis of 2-substituted-7-heptyloxy-4, 5-dihydro-[1,2,4]-triazolo[4,3-a]quinolin-1(2H)-ones with anticonvulsant activity. Arch. Pharm. 2007, 340, 491-495. [CrossRef] [PubMed] 
17. Guan, L.P.; Jin, Q.H.; Tian, G.R.; Chai, K.Y.; Quan, Z.S. Synthesis of some quinoline-2(1H)-one and 1,2,4-triazolo[4,3-a] quinoline derivatives as potent anticonvulsants. J. Pharm. Pharm. Sci. 2007, 10, 254-256. [PubMed]

18. Guan, L.P.; Jin, Q.H.; Wang, S.F.; Li, F.N.; Quan, Z.S. Synthesis and anticonvulsant activity of 5-phenyl-[1,2,4]-triazolo[4,3-a]quinolines. Arch. Pharm. 2008, 341, 774-779. [CrossRef] [PubMed]

19. Guo, L.J.; Wei, C.X.; Jia, J.H.; Zhao, L.M.; Quan, Z.S. Design and synthesis of 5-alkoxy-[1,2,4]triazolo[4,3- $a]$ quinoline derivatives with anticonvulsant activity. Eur. J. Med. Chem. 2009, 44, 954-958. [CrossRef] [PubMed]

20. Sun, X.Y.; Zhang, L.; Wei, C.X.; Piao, H.R.; Quan, Z.S. Design, synthesis of 8-alkoxy-5,6-dihydrotriazino[4,3-a]quinolin-1-ones with anticonvulsant activity. Eur. J. Med. Chem. 2009, 44, 1265-1270. [CrossRef] [PubMed]

21. Wei, C.X.; Deng, X.Q.; Chai, K.Y.; Sun, Z.G.; Quan, Z.S. Synthesis and anticonvulsant activity of 1-formamide-triazolo[4,3-a]quinoline derivatives. Arch. Pharm. Res. 2010, 33, 655-662. [CrossRef] [PubMed]

22. Wang, S.B.; Deng, X.Q.; Zheng, Y.; Zhang, H.J.; Quan, Z.S. Synthesis and anticonvulsant activity evaluation of 8-alkoxy-5-(4H-1,2,4-triazol-4-yl)quinoline derivatives. Arch. Pharm. Res. 2013, 36, 32-40. [CrossRef] [PubMed]

23. Deng, X.Q.; Song, M.X.; Zheng, Y.; Quan, Z.S. Design, synthesis and evaluation of the antidepressant and anticonvulsant activities of triazole-containing quinolinones. Eur. J. Med. Chem. 2014, 73, 217-224. [CrossRef] [PubMed]

24. He, X.; Zhong, M.; Yang, J.; Wu, Z.; Xiao, Y.; Guo, H.; Hu, X. Synthesis and anticonvulsant activity of 1-(2-(8-(benzyloxy)quinolin-2-yl)-1-butyrylcyclopropyl)-3-substituted urea derivatives. Chem. Biol. Drug Des. 2012, 79, 771-779. [CrossRef] [PubMed]

25. He, X.; Zhong, M.; Zhang, T.; Yang, J.; Wu, Z.; Xiao, Y.; Guo, H.; Qiu, G.; Hu, X. Synthesis and anticonvulsant activity of 1-(8-(benzyloxy)quinolin-2-yl)-6-substituted-4,6-diazaspiro[2,4]heptane-5,7-diones. Eur. J. Med. Chem. 2012, 48, 338-346. [CrossRef] [PubMed]

26. Kumar, S.; Kaushik, D.; Bawa, S.; Khan, S.A. Design, synthesis and screening of quinoline-incorporated thiadiazole as a potential anticonvulsant. Chem. Biol. Drug Des. 2012, 79, 104-111. [CrossRef] [PubMed]

27. Ugale, V.G.; Bari, S.B. Quinazolines: New horizons in anticonvulsant therapy. Eur. J. Med. Chem. 2014, 80, 447-501. [CrossRef] [PubMed]

28. Vaidya, N.A.; Panos, C.H.; Kite, A.; Iturrian, W.B.; Blanton, C.D., Jr. Synthesis of 3,4-dihydro-4oxoquinazoline derivatives as potential anticonvulsants. J. Med. Chem. 1983, 26, 1422-1425. [CrossRef] [PubMed]

29. Wang, H.J.; Wei, C.X.; Deng, X.Q.; Li, F.L.; Quan, Z.S. Synthesis and evaluation on anticonvulsant and antidepressant activities of 5-Alkoxy-tetrazolo[1,5-a]quinazolines. Arch. Pharm. 2009, 342, 671-675. [CrossRef] [PubMed]

30. Zheng, Y.; Bian, M.; Deng, X.Q.; Wang, S.B.; Quan, Z.S. Synthesis and anticonvulsant activity evaluation of 5-phenyl-[1,2,4]triazolo[4,3-c]quinazolin-3-amines. Arch. Pharm. 2013, 346, 119-126. [CrossRef] [PubMed]

31. El-Azab, A.S.; Eltahir, K.E. Synthesis and anticonvulsant evaluation of some new 2,3,8-trisubstituted-4(3H)quinazoline derivatives. Bioorg. Med. Chem. Lett. 2012, 22, 327-333. [CrossRef] [PubMed]

32. El-Azab, A.S.; Eltahir, K.E. Design and synthesis of novel 7-aminoquinazoline derivatives: Antitumor and anticonvulsant activities. Bioorg. Med. Chem. Lett. 2012, 22, 1879-1885. [CrossRef] [PubMed]

33. Abbas, S.-S.; Awadallah, F.M.; Ibrahim, N.A.; Said, E.G.; Kamel, G. Design and synthesis of some 3-substituted-2-[(2,4-dichlorophenoxy)-methyl]quinazolin-4(3H)-one derivatives as potential anticonvulsant agents. Chem. Pharm. Bull. 2013, 61, 679-687. [CrossRef]

34. Rajasekaran, A.; Rajamanickam, V.; Darlinquine, S. Synthesis of some new thioxoquinazolinone derivatives and a study on their anticonvulsant and antimicrobial activities. Eur. Rev. Med. Pharmacol. Sci. 2013, 17, 95-104. [PubMed]

35. Prashanth, M.K.; Madaiah, M.; Revanasiddappa, H.D.; Veeresh, B. Synthesis, anticonvulsant, antioxidant and binding interaction of novel $\mathrm{N}$-substituted methylquinazoline-2,4 $(1 \mathrm{H}, 3 \mathrm{H})$-dione derivatives to bovine serum albumin: A structure-activity relationship study. Spectrochim. Acta A Mol. Biomol. Spectrosc. 2013, 110, 324-332. [CrossRef] [PubMed] 
36. Malik, S.; Bahare, R.S.; Khan, S.A. Design, synthesis and anticonvulsant evaluation of N-(benzo[d]thiazol-2ylcarbamoyl)-2-methyl-4-oxoquinazoline-3(4H)-carbothioamide derivatives: A hybrid pharmacophore approach. Eur. J. Med. Chem. 2013, 67, 1-13. [CrossRef] [PubMed]

37. Saravanan, G.; Alagarsamy, V.; Prakash, C.R. Design, synthesis and anticonvulsant activities of novel 1-(substituted/unsubstituted-benzylidene)-4-(4-(6,8-dibromo-2-(methyl/phenyl)-4-oxo-quinazolin-3(4H)yl)phenyl) semicarbazide derivatives. Bioorg. Med. Chem. Lett. 2012, 22, 3072-3078. [CrossRef] [PubMed]

38. Wilby, M.J.; Hutchinson, P.J. The pharmacology of chlormethiazole: A potential neuroprotective agent? CNS Drug Rev. 2004, 10, 281-294. [CrossRef] [PubMed]

39. Harnett, J.J.; Roubert, V.; Dolo, C.; Charnet, C.; Spinnewyn, B.; Cornet, S.; Rolland, A.; Marin, J.G.; Bigg, D.; Chabrier, P.E. Phenolic thiazoles as novel orally-active neuroprotective agents. Bioorg. Med. Chem. Lett. 2004, 14, 157-160. [CrossRef] [PubMed]

40. Siddiqui, N.; Rana, A.; Khan, S.A.; Bhat, M.A.; Haque, S.E. Synthesis of benzothiazole semicarbazones as novel anticonvulsants-The role of hydrophobic domain. Bioorg. Med. Chem. Lett. 2007, 17, 4178-4182. [CrossRef] [PubMed]

41. Rana, A.; Siddiqui, N.; Khan, S.A.; Ehtaishamul Haque, S.; Bhat, M.A. N-\{[(6-substituted-1,3-benzothiazole2-yl)amino]carbonothioyl\}-2/4-substituted benzamides: Synthesis and pharmacolo-gical evaluation. Eur. J. Med. Chem. 2008, 43, 1114-1122. [CrossRef] [PubMed]

42. Liu, D.C.; Deng, X.Q.; Wang, S.B.; Quan, Z.S. Synthesis and anticonvulsant activity evaluation of 7-alkoxy[1,2,4]triazolo[3,4-b]benzothiazol-3(2H)-ones. Arch. Pharm. 2014, 347, 268-275. [CrossRef] [PubMed]

43. Siddiqui, N.; Rana, A.; Khan, S.A.; Haque, S.E.; Arshad, M.F.; Ahmed, S.; Ahsan, W. Synthesis and preliminary screening of benzothiazol-2-yl thiadiazole derivatives for anticonvulsant activity. Acta Pharm. 2009, 59, 441-451. [CrossRef] [PubMed]

44. Siddiqui, N.; Pandeya, S.N.; Khan, S.A.; Stables, J.; Rana, A.; Alam, M.; Arshad, M.F.; Bhat, M.A. Synthesis and anticonvulsant activity of sulfonamide derivatives-hydrophobic domain. Bioorg. Med. Chem. Lett. 2007, 17, 255-259. [CrossRef] [PubMed]

45. Farag, A.A.; Abd-Alrahman, S.N.; Ahmed, G.F.; Ammar, R.M.; Ammar, Y.A.; Abbas, S.Y. Synthesis of some azoles incorporating a sulfonamide moiety as anticonvulsant agents. Arch. Pharm. 2012, 345, 703-712. [CrossRef] [PubMed]

46. Siddiqui, N.; Arshad, M.F.; Khan, S.A. Synthesis of some new coumarin incorporated thiazolyl semicarbazones as anticonvulsants. Acta Pol. Pharm. 2009, 66, 161-167. [PubMed]

47. Hassan, M.Z.; Khan, S.A.; Amir, M. Design, synthesis and evaluation of $N$-(substituted benzothiazol-2-yl)amides as anticonvulsant and neuroprotective. Eur. J. Med. Chem. 2012, 58, 206-213. [CrossRef] [PubMed]

48. Deng, X.Q.; Song, M.X.; Wei, C.X.; Li, F.N.; Quan, Z.S. Synthesis and anticonvulsant activity of 7-alkoxy-triazolo-[3,4-b]benzo[d]thiazoles. Med. Chem. 2010, 6, 313-320. [CrossRef] [PubMed]

49. Siddiqui, N.; Rana, A.; Khan, S.A.; Haque, S.E.; Alam, M.S.; Ahsan, W.; Ahmed, S. Synthesis of 8-substituted-4-(2/4-substituted phenyl)-2H-[1,3,5]triazino[2,1-b][1,3]benzothiazole-2-thiones and their anticonvulsant, anti-nociceptive, and toxicity evaluation in mice. J. Enzym. Inhib. Med. Chem. 2009, 24, 1344-1350. [CrossRef] [PubMed]

50. Zhang, L.Q.; Guan, L.P.; Wei, C.X.; Deng, X.Q.; Quan, Z.S. Synthesis and anticonvulsant activity of some 7-alkoxy-2H-1,4-benzothiazin-3(4H)-ones and 7-alkoxy-4H-[1,2,4]triazolo[4,3-d]benzo[b][1,4]thiazines. Chem. Pharm. Bull. 2010, 58, 326-331. [CrossRef] [PubMed]

51. Siddiqui, N.; Ali, R.; Arshad, M.F.; Ahsan, W.; Ahmed, S.; Alam, M.S. anticonvulsant and toxicity evaluation of newer $4 H$-benzo[1,4]oxazin-3-ones: The effect of two hydrogen bonding domains. Arch. Pharm. 2010, 343, 657-663. [CrossRef] [PubMed]

52. Piao, Z.T.; Guan, L.P.; Zhao, L.M.; Piao, H.R.; Quan, Z.S. Synthesis of novel 7-benzylamino-2H-1,4benzoxazin-3(4H)-ones as anticonvulsant agents. Eur. J. Med. Chem. 2008, 43, 1216-1221. [CrossRef] [PubMed]

53. Zarghi, A.; Hajimahdi, Z. Substituted oxadiazoles: A patent review (2010-2012). Expert. Opin. Ther. Pat. 2013, 23, 1209-1232. [CrossRef] [PubMed] 
54. Bhat, M.A.; Siddiqui, N.; Khan, S.A. Synthesis of novel 3-(4-acetyl-5H/methyl-5-substituted phenyl-4,5-dihydro-1,3,4-oxadiazol-2-yl)-2H-chromen-2-ones as potential anticonvulsant agents. Acta Pol. Pharm. 2008, 65, 235-239. [PubMed]

55. Tabatabai, S.A.; Barghi Lashkari, S.; Zarrindast, M.R.; Gholibeikian, M.; Shafiee, A. Design, Synthesis and Anticonvulsant Activity of 2-(2-Phenoxy) phenyl-1,3,4-oxadiazole Derivatives. Iran J. Pharm. Res. 2013, 12, 105-111. [PubMed]

56. Harish, K.P.; Mohana, K.N.; Mallesha, L.; Prasanna Kumar, B.N. Synthesis of novel 1-[5-(4-methoxy-phenyl)-[1,3,4]oxadiazol-2-yl]-piperazine derivatives and evaluation of their in vivo anticonvulsant activity. Eur. J. Med. Chem. 2013, 65, 276-283. [CrossRef] [PubMed]

57. Harish, K.P.; Mohana, K.N.; Mallesha, L.; Veeresh, B. Synthesis and in vivo anticonvulsant activity of 2-methyl-2-[3-(5-piperazin-1-yl-[1,3,4]oxadiazol-2-yl)-phenyl]-propionitrile derivatives. Arch. Pharm. 2014, 347, 256-267. [CrossRef] [PubMed]

58. Siddiqui, N.; Alam, M.S.; Ahsan, W. Synthesis, anticonvulsant and toxicity evaluation of 2-(1H-indol3-yl)acetyl- $N$-(substituted-phenyl)hydrazine carbothioamides and their related heterocyclic derivatives. Acta Pharm. 2008, 58, 445-454. [CrossRef] [PubMed]

59. Siddiqui, N.; Sarafroz, M.; Alam, M.M.; Ahsan, W. Synthesis, anticonvulsant and neurotoxicity evaluation of 5-carbomethoxybenzoxazole derivatives. Acta Pol. Pharm. 2008, 65, 449-455. [PubMed]

60. Wei, C.X.; Guan, L.P.; Jia, J.H.; Chai, K.Y.; Quan, Z.S. Synthesis of 2-substituted-6-(4H-1,2,4-triazol-4-yl) benzo[d]oxazoles as potential anticonvulsant agents. Arch. Pharm. Res. 2009, 32, 23-31. [CrossRef] [PubMed]

61. Malik, S.; Ahuja, P.; Sahu, K.; Khan, S.A. Design and synthesis of new of 3-(benzo[d]isoxazol-3-yl)1-substituted pyrrolidine-2,5-dione derivatives as anticonvulsants. Eur. J. Med. Chem. 2014, 84, 42-50. [CrossRef] [PubMed]

62. Malik, S.; Khan, S.A. Design and synthesis of (5-amino-1,2,4-triazin-6-yl)(2-(benzo[d]isoxazol-3-yl)pyrrolidin1-yl)methanone derivatives as sodium channel blocker and anticonvulsant agents. J. Enzym. Inhib. Med. Chem. 2014, 29, 505-516. [CrossRef] [PubMed]

63. Naeem, S.; Akhtar, S.; Mushtaq, N.; Kamil, A.; Zafar, S.; Anwar, S.; Arif, M. Synthesis of novel derivatives of 4-Pyridine carboxylic acid hydrazide and their activity on central nervous system. Pak. J. Pharm. Sci. 2014, 27, 1401-1408. [PubMed]

64. Prasanthi, G.; Prasad, K.V.; Bharathi, K. Design, synthesis and evaluation of dialkyl 4-(benzo[d] dioxol-6-yl)-1,4-dihydro-2,6-dimethyl-1-substituted pyridine-3,5-dicarboxylates as potential anticonvulsants and their molecular properties prediction. Eur. J. Med. Chem. 2013, 66, 516-525. [CrossRef] [PubMed]

65. Prasanthi, G.; Prasad, K.V.; Bharathi, K. Synthesis, anticonvulsant activity and molecular properties prediction of dialkyl 1-(di(ethoxycarbonyl)methyl)-2,6-dimethyl-4-substituted-1,4-dihydropyridine-3, 5-dicarboxylates. Eur. J. Med. Chem. 2014, 73, 97-104. [CrossRef] [PubMed]

66. Guan, L.P.; Zhang, R.P.; Sun, Y.; Chang, Y.; Sui, X. Synthesis and studies on the anticonvulsant activity of 5-alkoxy-[1,2,4]triazolo[4,3-a]pyridine derivatives. Arzneimittelforschung 2012, 62, 372-377. [CrossRef] [PubMed]

67. Farag, A.M.; Mayhoub, A.S.; Barakat, S.E.; Bayomi, A.H. Regioselective synthesis and antitumor screening of some novel N-phenylpyrazole derivatives. Bioorg. Med. Chem. 2008, 16, 881-889. [CrossRef] [PubMed]

68. Boschi, D.; Guglielmo, S.; Aiello, S.; Morace, G.; Borghi, E.; Fruttero, R. Synthesis and in vitro antimicrobial activities of new (cyano-NNO-azoxy)pyrazole derivatives. Bioorg. Med. Chem. Lett. 2011, 21, 3431-3434. [CrossRef] [PubMed]

69. Taj, T.; Kamble, R.R.; Gireesh, T.M.; Hunnur, R.K.; Margankop, S.B. One-pot synthesis of pyrazoline derivatised carbazoles as antitubercular, anticancer agents, their DNA cleavage and antioxidant activities. Eur. J. Med. Chem. 2011, 46, 4366-4373. [CrossRef] [PubMed]

70. Cunico, W.; Cechinel, C.A.; Bonacorso, H.G.; Martins, M.A.; Zanatta, N.; de Souza, M.V.; Freitas, I.O.; Soares, R.P.; Krettli, A.U. Antimalarial activity of 4-(5-trifluoromethyl-1H-pyrazol-1-yl)-chloroquine analogues. Bioorg. Med. Chem. Lett. 2006, 16, 649-653. [CrossRef] [PubMed]

71. Kaushik, D.; Khan, S.A.; Chawla, G.; Kumar, S. N'-[(5-chloro-3-methyl-1-phenyl-1H-pyrazol-4-yl)methylene] 2/4-substituted hydrazides: Synthesis and anticonvulsant activity. Eur. J. Med. Chem. 2010, 45, 3943-3949. [CrossRef] [PubMed] 
72. Siddiqui, N.; Alam, P.; Ahsan, W. Design, synthesis, and in vivo pharmacological screening of N,3-(substituted-diphenyl)-5-phenyl-1H-pyrazoline-1-carbothioamide derivatives. Arch. Pharm. 2009, 342, 173-181. [CrossRef] [PubMed]

73. Ahsan, M.J.; Khalilullah, H.; Stables, J.P.; Govindasamy, J. Synthesis and anticonvulsant activity of 3a,4-dihydro-3H-indeno[1,2-c]pyrazole-2-carboxamide/carbothioamide analogues. J. Enzym. Inhib. Med. Chem. 2013, 28, 644-650. [CrossRef] [PubMed]

74. Farghaly, A.R.; Esmail, S.; Abdel-Zaher, A.; Abdel-Hafez, A.; El-Kashef, H. Synthesis and anticonvulsant activity of some new pyrazolo[3,4-b]pyrazines and related heterocycles. Bioorg. Med. Chem. 2014, 22, 2166-2175. [CrossRef] [PubMed]

75. Navidpour, L.; Shadnia, H.; Shafaroodi, H.; Amini, M.; Dehpour, A.R.; Shafiee, A. Design, synthesis, and biological evaluation of substituted 2-alkylthio-1,5-diarylimidazoles as selective COX-2 inhibitors. Bioorg. Med. Chem. 2007, 15, 1976-1982. [CrossRef] [PubMed]

76. Schiaffella, F.; Macchiarulo, A.; Milanese, L.; Vecchiarelli, A.; Fringuelli, R. Novel ketoconazole analogues based on the replacement of 2,4-dichlorophenyl group with 1,4-benzothiazine moiety: Design, synthesis, and microbiological evaluation. Bioorg. Med. Chem. 2006, 14, 5196-5203. [CrossRef] [PubMed]

77. Thenmozhiyal, J.C.; Wong, P.T.; Chui, W.K. Anticonvulsant activity of phenylmethyl-enehydantoins: A structure-activity relationship study. J. Med. Chem. 2004, 47, 1527-1535. [CrossRef] [PubMed]

78. Karakurt, A.; Ozalp, M.; Işik, S.; Stables, J.P.; Dalkara, S. Synthesis, anticonvulsant and antimicrobial activities of some new 2-acetylnaphthalene derivatives. Bioorg. Med. Chem. 2010, 18, 2902-2911. [CrossRef] [PubMed]

79. Husain, A.; Siddiqui, N.; Sarafroz, M.; Khatoon, Y.; Rasid, M.; Ahmad, N. Synthesis, anticonvulsant and neurotoxicity screening of some novel 1,2,4-trisubstituted-1H-imidazole derivatives. Acta Pol. Pharm. 2011, 68, 657-663. [PubMed]

80. Amir, M.; Ali, I.; Hassan, M.Z. Imidazole incorporated semicarbazone derivatives as a new class of anticonvulsants: Design, synthesis and in vivo screening. Med. Chem. 2013, 9, 571-580. [CrossRef] [PubMed]

81. Ulloora, S.; Shabaraya, R.; Aamir, S.; Adhikari, A.V. New imidazo[1,2-a]pyridines carrying active pharmacophores: Synthesis and anticonvulsant studies. Bioorg. Med. Chem. Lett. 2013, 23, 1502-1506. [CrossRef] [PubMed]

82. Ulloora, S.; Shabaraya, R.; Adhikari, A.V. Facile synthesis of new imidazo[1,2-a] pyridines carrying 1,2,3-triazoles via click chemistry and their antiepileptic studies. Bioorg. Med. Chem. Lett. 2013, 23, 3368-3372. [CrossRef] [PubMed]

83. Kaur, R.; Kaur, P.; Sharma, S.; Singh, G.; Mehndiratta, S.; Nepali, K. Anti-Cancer Pyrimidines in Diverse Scaffolds: A Review of Patent Literature. Recent Pat. Anticancer Drug Discov. 2015, 10, 23-71. [CrossRef] [PubMed]

84. Nofal, Z.M.; Fahmy, H.H.; Zarea, E.S.; El-Eraky, W. Synthesis of new pyrimidine derivatives with evaluation of their anti-inflammatory and analgesic activities. Acta Pol. Pharm. 2011, 68, 507-517. [PubMed]

85. Rahaman, S.A.; Rajendra Pasad, Y.; Kumar, P.; Kumar, B. Synthesis and anti-histaminic activity of some novel pyrimidines. Saudi Pharm. J. 2009, 17, 255-258. [CrossRef] [PubMed]

86. Alam, O.; Mullick, P.; Verma, S.P.; Gilani, S.J.; Khan, S.A.; Siddiqui, N.; Ahsan, W. Synthesis, anticonvulsant and toxicity screening of newer pyrimidine semicarbazone derivatives. Eur. J. Med. Chem. 2010, 45, 2467-2472. [CrossRef] [PubMed]

87. Deng, X.Q.; Quan, L.N.; Song, M.X.; Wei, C.X.; Quan, Z.S. Synthesis and anticonvulsant activity of 7-phenyl-6,7-dihydro-[1,2,4]triazolo[1,5-a]pyrimidin-5(4H)-ones and their derivatives. Eur. J. Med. Chem. 2011, 46, 2955-2963. [CrossRef] [PubMed]

88. Jiang, N.; Deng, X.Q.; Li, F.N.; Quan, Z.S. Synthesis of Novel 7-Substituted-5-phenyl-[1,2,4] triazolo[1,5-a] Pyrimidines with Anticonvulsant Activity. Iran. J. Pharm. Res. 2012, 11, 799-806. [PubMed]

89. Shaquiquzzaman, M.; Khan, S.A.; Amir, M.; Alam, M.M. Synthesis, anticonvulsant and neurotoxicity evaluation of some new pyrimidine-5-carbonitrile derivatives. Saudi Pharm. J. 2012, 20, 149-154. [CrossRef] [PubMed]

90. Shaquiquzzaman, M.; Khan, S.A.; Amir, M.; Alam, M.M. Synthesis and anticonvulsant activity of some 2-(2-\{1-[substitutedphenyl]ethylidene\}hydrazinyl)-4-(4-methoxy-phenyl)-6-oxo-1,6-dihydro-pyrimidine-5carbonitrile. J. Enzym. Inhib. Med. Chem. 2012, 27, 825-831. [CrossRef] [PubMed] 
91. Sivakumar, R.; Kishore Gnanasam, S.; Ramachandran, S.; Leonard, J.T. Pharmacological evaluation of some new 1-substituted-4-hydroxy-phthalazines. Eur. J. Med. Chem. 2002, 37, 793-801. [CrossRef]

92. Dogruer, D.S.; Kupeli, E.; Yesilada, E.; Sahin, M.F. Synthesis of new 2-[1(2H)-phthalazinon-2-yl]acetamide and 3-[1(2H)-phthalazinon-2-yl]propanamide derivatives as antinociceptive and anti-inflammatory agents. Arch. Pharm. 2004, 337, 303-310. [CrossRef] [PubMed]

93. Sönmez, M.; Berber, I.; Akbaş, E. Synthesis, antibacterial and antifungal activity of some new pyridazinone metal complexes. Eur. J. Med. Chem. 2006, 41, 101-105. [CrossRef] [PubMed]

94. Zhang, L.; Guan, L.P.; Sun, X.Y.; Wei, C.X.; Chai, K.Y.; Quan, Z.S. Synthesis and anticonvulsant activity of 6-alkoxy-[1,2,4]triazolo[3,4-a]phthalazines. Chem. Biol. Drug Des. 2009, 73, 313-319. [CrossRef] [PubMed]

95. Sun, X.Y.; Wei, C.X.; Deng, X.Q.; Sun, Z.G.; Quan, Z.S. Evaluation of the anticonvulsant activity of 6-(4-chlorophenyoxy)-tetrazolo[5,1-a]phthalazine in various experimental seizure models in mice. Pharmacol. Rep. 2010, 62, 273-277. [CrossRef]

96. Bian, M.; Deng, X.Q.; Gong, G.H.; Wei, C.X.; Quan, Z.S. Synthesis and anticonvulsant activity evaluation of 6-substituted-[1,2,4]triazolo[3,4-a](tetrazolo[5,1-a])phthalazine derivatives. J. Enzym. Inhib. Med. Chem. 2013, 28, 792-800. [CrossRef] [PubMed]

97. Abdel-Rahman, R.M. Chemistry of uncondensed 1,2,4-triazines: Part II sulfur containing 5-oxo-1,2,4triazin-3-yl moiety, An overview. Phosphor Sulfur Silicon 2000, 166, 315-357. [CrossRef]

98. Abdel-Rahman, R.M.; Seada, M.; el-Gendy, Z.; Islam, I.E.; Mahmoud, M.B. Synthesis of some new 4,6-disubstituted-1,2,4-triazin-3,5(2H)-diones and related compounds of potential antifungal activity. Farmaco 1993, 48, 407-416. [CrossRef] [PubMed]

99. Mullick, P.; Khan, S.A.; Begum, T.; Verma, S.; Kaushik, D.; Alam, O. Synthesis of 1,2,4-triazine derivatives as potential anti-anxiety and anti-inflammatory agents. Acta Pol. Pharm. 2009, 66, 379-385. [PubMed]

100. Kaushik, D.; Khan, S.A.; Chawla, G. Design \& synthesis of 2-(substituted-aryloxy)-5-(substituted benzylidene)-3-phenyl-2,5-dihydro- $1 H-[1,2,4]$ triazin-6-one as potential anticonvulsant agents. Eur. J. Med. Chem. 2010, 45, 3960-3969.

101. Amir, M.; Ali, I.; Hassan, M.Z.; Mulakayala, N. Design, Synthesis, and Biological Evaluation of Hydrazone Incorporated 1,2,4-Triazines as Anticonvulsant Agents. Arch. Pharm. 2014, 347, 958-968. [CrossRef] [PubMed]

102. Ahuja, P.; Siddiqui, N. Anticonvulsant evaluation of clubbed indole-1,2,4-triazine derivatives: A synthetic approach. Eur. J. Med. Chem. 2014, 80, 509-522. [CrossRef] [PubMed]

103. Luszczki, J.J.; Plech, T.; Wujec, M. Effect of 4-(4-bromophenyl)-5-(3-chlorophenyl)-2,4-dihydro-3H-1,2,4triazole-3-thione on the anticonvulsant action of different classical antiepileptic drugs in the mouse maximal electroshock-induced seizure model. Eur. J. Pharmacol. 2012, 690, 99-106. [CrossRef] [PubMed]

104. Luszczki, J.J.; Plech, T.; Wujec, M. Influence of 5-(3-chlorophenyl)-4-(4-methylphenyl)-2,4-dihydro-3H-1,2,4triazole-3-thione on the anticonvulsant action of 4 classical antiepileptic drugs in the mouse maximal electroshock-induced seizure model. Pharmacol. Rep. 2012, 64, 970-978. [CrossRef]

105. Siddiqui, N.; Ahsan, W. Triazole incorporated thiazoles as a new class of anticonvulsants: Design, synthesis and in vivo screening. Eur. J. Med. Chem. 2010, 45, 1536-1543. [CrossRef] [PubMed]

106. Plech, T.; Luszczki, J.J.; Wujec, M.; Flieger, J.; Pizoń, M. Synthesis, characterization and preliminary anticonvulsant evaluation of some 4-alkyl-1,2,4-triazoles. Eur. J. Med. Chem. 2013, 60, 208-215. [CrossRef] [PubMed]

107. Plech, T.; Kaproń, B.; Luszczki, J.J.; Wujec, M.; Paneth, A.; Siwek, A.; Kołaczkowski, M.; Zołnierek, M.; Nowak, G. Studies on the anticonvulsant activity and influence on GABA-ergic neurotransmission of 1,2,4-triazole-3-thione-based compounds. Molecules 2014, 19, 11279-11299. [CrossRef] [PubMed]

108. Pandeya, S.N.; Smitha, S.; Jyoti, M.; Sridhar, S.K. Biological activities of isatin and its derivatives. Acta Pharm. 2005, 55, 27-46. [PubMed]

109. Abadi, A.H.; Abou-Seri, S.M.; Abdel-Rahman, D.E.; Klein, C.; Lozach, O.; Meijer, L. Synthesis of 3-substituted-2-oxoindole analogues and their evaluation as kinase inhibitors, anticancer and antiangiogenic agents. Eur. J. Med. Chem. 2006, 41, 296-305. [CrossRef] [PubMed]

110. Giordano, C.; Marchiò, M.; Timofeeva, E.; Biagini, G. Neuroactive peptides as putative mediators of antiepileptic ketogenic diets. Front. Neurol. 2014, 5, 63. [CrossRef] [PubMed] 
111. Prakash, C.R.; Raja, S.; Saravanan, G. Anticonvulsant activity of novel 1-(substituted benzylidene)-4(1-(morpholino/piperidino-methyl)-2,3-dioxoindolin-5-yl) semicarbazide derivatives in mice and rats acute seizure models. Chem. Biol. Drug Des. 2012, 80, 524-532. [CrossRef] [PubMed]

112. He, X.; Zhong, M.; Zhang, T.; Wu, W.; Wu, Z.; Xiao, Y.; Hu, X. Synthesis and anticonvulsant activity of ethyl 1-(2-arylhydrazinecarboxamido)-2,2-dimethylcyclopropanecarboxylate derivatives. Eur. J. Med. Chem. 2012, 54, 542-548. [CrossRef] [PubMed]

113. Zhong, M.; Zhang, Y.; He, X. Synthesis and anticonvulsant activity of ethyl 2,2-dimethyl-1(2-substitutedhydrazinecarboxamido)cyclopropanecarboxylate derivatives. Chem. Biol. Drug Des. 2014, 84, 234-241. [CrossRef] [PubMed]

114. Ilieva, E.D.; Petkova, N.I.; Nikolova, R.D. A new and efficient method for the synthesis of 3,4-disubstituted pyrrolidine-2,5-diones. Molecules 2012, 17, 4936-4949. [CrossRef] [PubMed]

115. Obniska, J.; Lesyk, R.; Atamanyuk, D.; Kamiński, K. Synthesis and anticonvulsant activity of a series of $N$-substituted bicyclo[2,2,1] hept-5-ene-2,3-dicarboximides. Acta Pol. Pharm. 2005, 62, 213-219. [PubMed]

116. Obniska, J.; Kamiński, K. Synthesis and anticonvulsant properties of new $N$-phenylamino derivatives of 2-azaspiro[4.4]nonane, 2-azaspiro[4.5]decane-1,3-dione and 3-cyclohexylpyrrolidine-2,5-dione. Part IV. Acta Pol. Pharm. 2006, 63, 101-108. [PubMed]

117. Obniska, J.; Kamiński, K. Lipophilicity characterization of new N-phenylamino-azaspiranes as potential anticonvulsant agents. Biomed. Chromatogr. 2006, 20, 1185-1191. [CrossRef] [PubMed]

118. Obniska, J.; Kamiński, K.; Chlebek, I. Synthesis and anticonvulsant activity of new spirosuccinimides differently substituted at the imide nitrogen atom. Acta Pol. Pharm. 2009, 66, 663-669. [PubMed]

119. Obniska, J.; Jurczyk, S.; Zejc, A.; Kamiński, K.; Tatarczyńska, E.; Stachowicz, K. Anticonvulsant properties of $\mathrm{N}$-(4-methylpiperazin-1-yl)- and $\mathrm{N}$-[3-(4-methyl-piperazin-1-yl)propyl] derivatives of 3-aryland 3-spirocycloalkyl-pyrrolidine -2,5-dione. Pharmacol. Rep. 2005, 57, 170-175. [PubMed]

120. Obniska, J.; Kamiński, K.; Tatarczyńska, E. Impact of aromatic substitution on the anticonvulsant activity of new N-(4-arylpiperazin-1-yl)-alkyl-2-azaspiro[4,5]decane-1,3-dione derivatives. Pharmacol. Rep. 2006, 58, 207-214. [PubMed]

121. Obniska, J.; Chlebek, I.; Pichór, J.; Kopytko, M.; Kamiński, K. Synthesis, physicochemical and anticonvulsant properties of new N-[(4-arylpiperazin-1-yl)alkyl]-3-phenyl- and 3-(3-methyl-phenyl)pyrrolidine-2,5-diones. Acta Pol. Pharm. 2009, 66, 639-647. [PubMed]

122. Obniska, J.; Kopytko, M.; Zagórska, A.; Chlebek, I.; Kamiński, K. Synthesis and anticonvulsant properties of new Mannich bases derived from 3-aryl-pyrrolidine-2,5-diones. Part I. Arch. Pharm. 2010, 343, 333-341. [CrossRef] [PubMed]

123. Obniska, J.; Rzepka, S.; Kamiński, K. Synthesis and anticonvulsant activity of new N-Mannich bases derived from 3-(2-fluorophenyl)- and 3-(2-bromophenyl)-pyrrolidine-2,5-diones. Part II. Bioorg. Med. Chem. 2012, 20, 4872-4880. [CrossRef] [PubMed]

124. Obniska, J.; Kaminski, K.; Skrzynska, D.; Pichor, J. Synthesis and anticonvulsant activity of new $\mathrm{N}$-[(4-arylpiperazin-1-yl)-alkyl]derivatives of 3-phenyl-pyrrolidine-2,5-dione. Eur. J. Med. Chem. 2009, 44, 2224-2233. [CrossRef] [PubMed]

125. Obniska, J.; Kaminski, K.; Hondo, L.; Zejc, A. Synthesis, physicochemical and anticonvulsant properties of new N-4-arylpiperazin-1-yl amides of (2-aza-1,3-dioxospiro[4.4]non-2-yl)- and [4.5]dec-2-yl)-propionic acid. Arch. Pharm. 2007, 340, 404-408. [CrossRef] [PubMed]

126. Obniska, J.; Chlebek, I.; Kamiński, K. Synthesis and anticonvulsant properties of new mannich bases derived from 3,3-disubstituted pyrrolidine-2,5-diones. Part IV. Arch. Pharm. 2012, 345, 713-722. [CrossRef] [PubMed]

127. Obniska, J.; Chlebek, I.; Kamiński, K.; Karolak-Wojciechowska, J. Synthesis and anticonvulsant properties of new N-Mannich bases derived from 3,3-diphenyl- and 3-ethyl-3-methyl-pyrrolidine-2,5-diones. Part III. Arch. Pharm. 2013, 346, 71-82. [CrossRef] [PubMed]

128. Kamiński, K.; Obniska, J.; Dybała, M. Synthesis, physicochemical and anticonvulsant properties of new $\mathrm{N}$-phenylamino derivatives of 2-azaspiro[4.4]nonane- and [4.5]decane-1,3-diones: Part V. Eur. J. Med. Chem. 2008, 43, 53-61. [CrossRef] [PubMed]

129. Kaminski, K.; Obniska, J.; Zagorska, A.; Maciag, D. Synthesis, physicochemical and anticonvulsant properties of new $\mathrm{N}$-(pyridine-2-yl) derivatives of 2-azaspiro[4.4]nonane and [4.5]decane-1,3-dione. Part II. Arch. Pharm. 2006, 339, 255-261. [CrossRef] [PubMed] 
130. Kamiński, K.; Obniska, J. Design, synthesis, and anticonvulsant activity of $N$-phenylamino derivatives of 3,3-dialkyl-pyrrolidine-2,5-diones and hexahydro-isoindole-1,3-diones. Bioorg. Med. Chem. 2008, 16, 4921-4931. [CrossRef] [PubMed]

131. Kamiński, K.; Obniska, J.; Chlebek, I.; Wiklik, B.; Rzepka, S. Design, synthesis and anticonvulsant properties of new N-Mannich bases derived from 3-phenylpyrrolidine-2,5-diones. Bioorg. Med. Chem. 2013, 21, 6821-6830. [CrossRef] [PubMed]

132. Kamiński, K.; Obniska, J.; Chlebek, I.; Liana, P.; Pękala, E. Synthesis and biological properties of new $N$-Mannich bases derived from 3-methyl-3-phenyl- and 3,3-dimethyl-succinimides. Part V. Eur. J. Med. Chem. 2013, 66, 12-21. [CrossRef] [PubMed]

133. Rybka, S.; Obniska, J.; Rapacz, A.; Filipek, B.; Kamiński, K. Synthesis, Physicochemical, and Anticonvulsant Properties of New N-Mannich Bases Derived from Pyrrolidine-2,5-dione and Its 3-Methyl Analog. Arch. Pharm. 2014, 347, 768-776. [CrossRef] [PubMed]

134. Ware, E. The chemistry of the hydantoins. Chem. Rev. 1950, 46, 403-470. [CrossRef] [PubMed]

135. Khodair, A.I. Synthesis of arylidenehydrazono- and glycopyranosylhydrazino-sulfonyl-benzylidene-2, 4-imidazolidinediones as potential antiviral and antitumoral agents. Carbohydr. Res. 1998, 306, 567-573. [PubMed]

136. Comber, R.N.; Reynolds, R.C.; Friedrich, J.D.; Manguikian, R.A.; Buckheit, R.W., Jr.; Truss, J.W.; Shannon, W.M.; Secrist, J.A. 5,5-disubstituted hydantoins: Syntheses and anti-HIV activity. J. Med. Chem. 1992, 35, 3567-3572. [CrossRef] [PubMed]

137. Oh, C.H.; Kim, H.J.; Hong, S.Y.; Lee, Y.H.; Cho, J.K.; Cho, J.H. New 1 beta-methyl-carbapenems having a hydantoin moiety. Arch. Pharm. 1995, 328, 385-387. [CrossRef]

138. He, X.; Qiu, G.; Yang, J.; Xiao, Y.; Wu, Z.; Qiu, G.; Hu, X. Synthesis and anticonvulsant activity of new 6-methyl-1-substituted-4,6-diazaspiro[2,4]heptane-5,7-diones. Eur. J. Med. Chem. 2010, 45, 3818-3830. [CrossRef] [PubMed]

139. He, X.; Zhong, M.; Zhang, T.; Wu, W.; Wu, Z.; Yang, J.; Xiao, Y.; Pan, Y.; Qiu, G.; Hu, X. Synthesis and anticonvulsant activity of $\mathrm{N}$-3-arylamide substituted 5,5-cyclopropanespirohydantoin derivatives. Eur. J. Med. Chem. 2010, 45, 5870-5877. [CrossRef] [PubMed]

140. Botros, S.; Khalil, N.A.; Naguib, B.H.; El-Dash, Y. Synthesis and anticonvulsant activity of new phenytoin derivatives. Eur. J. Med. Chem. 2013, 60, 57-63. [CrossRef] [PubMed]

141. Byrtus, H.; Obniska, J.; Czopek, A.; Kamiński, K.; Pawłowski, M. Synthesis and anticonvulsant activity of new N-Mannich bases derived from 5-cyclopropyl-5-phenyl- and 5-cyclopropyl-5-(4-chlorophenyl)imidazolidine-2,4-diones. Bioorg. Med. Chem. 2011, 19, 6149-6156. [CrossRef] [PubMed]

142. Dhanawat, M.; Das, N.; Shrivastava, S.K. Design, synthesis, anticonvulsant screening and $5 \mathrm{HT}_{1 \mathrm{~A} / 2 \mathrm{~A}}$ receptor affinity of N(3)-substituted 2,4-imidazolidinediones and oxazolidinediones. Drug Discov. Ther. 2011, 5, 227-237. [CrossRef] [PubMed]

143. Botros, S.; Khalil, N.A.; Naguib, B.H.; El-Dash, Y. Phenytoin-based bivalent ligands: Design, synthesis and anticonvulsant activity. Arch. Pharm. Res. 2012, 35, 2105-2116. [CrossRef] [PubMed]

144. Byrtus, H.; Obniska, J.; Czopek, A.; Kamiński, K. Synthesis and anticonvulsant activity of new n-mannich bases derived from 5-cyclopropyl-5-phenyl-hydantoins. Arch. Pharm. 2011, 344, 231-241. [CrossRef] [PubMed]

145. Madaiah, M.; Prashanth, M.K.; Revanasiddappa, H.D.; Veeresh, B. Synthesis and evaluation of 3-[(2,4-dioxo-1,3,8-triazaspiro[4,6]undec-3-yl)methyl]benzonitrile derivatives as potential anticonvulsants. Arch. Pharm. 2013, 346, 200-209. [CrossRef] [PubMed]

146. Madaiah, M.; Prashanth, M.K.; Revanasiddappa, H.D.; Veeresh, B. Synthesis and pharmacological evaluation of novel 1'-[2-(difluoromethoxy)benzyl]-2' $H, 5^{\prime} H$-spiro[8-azabicyclo[3.2.1]octane-3,4'imidazolidine]-2', $5^{\prime}$-diones and their derivatives. Arch. Pharm. 2014, 347, 370-380. [CrossRef] [PubMed]

147. Choong, I.C.; Ellman, J.A. Synthesis of Alkoxylamines by Alkoxide Amination with 3,3'-Di-tertbutyloxaziridine. J. Org. Chem. 1999, 64, 6528-6529. [CrossRef] [PubMed]

148. Karakurt, A.; Dalkara, S.; Ozalp, M.; Ozbey, S.; Kendi, E.; Stables, J.P. Synthesis of some 1-(2-naphthyl)-2-(imidazole-1-yl)ethanone oxime and oxime ether derivatives and their anticonvulsant and antimicrobial activities. Eur. J. Med. Chem. 2001, 36, 421-433. [CrossRef] 
149. Karakurt, A.; Alagöz, M.A.; Sayoğlu, B.; Calış, U.; Dalkara, S. Synthesis of some novel 1-(2-naphthyl)-2(imidazol-1-yl)ethanone oxime ester derivatives and evaluation of their anticonvulsant activity. Eur. J. Med. Chem. 2012, 57, 275-282. [CrossRef] [PubMed]

150. Bansal, R.; Chauhan, P.; Sharma, R. Synthesis and anticonvulsant activity of O-alkylated derivatives of 1-(2-naphthyl)-2-(imidazol-1-yl)ethanone oxime. Arzneimittelforschung 2012, 62, 420-424. [CrossRef] [PubMed]

151. Karakurt, A.; Aytemir, M.D.; Stables, J.P.; Ozalp, M.; Betül Kaynak, F.; Ozbey, S.; Dalkara, S. Synthesis of some oxime ether derivatives of 1-(2-naphthyl)-2-(1,2,4-triazol-1-yl)ethanone and their anticonvulsant and antimicrobial activities. Arch. Pharm. 2006, 339, 513-520. [CrossRef] [PubMed]

152. Selçuk, G.U.M. A computational study on substituted diazabenzenes. Turk. J. Chem. 2011, 35, 803-808.

153. Kandile, N.G.; Zaky, H.T. New pyrano[2,3-c]pyridazine derivatives with antimicrobial activity synthesized using piperidine as the organocatalyst. J. Enzym. Inhib. Med. Chem. 2014, 30, 44-51. [CrossRef] [PubMed]

154. Li, D.; Zhan, P.; Liu, H.; Pannecouque, C.; Balzarini, J.; de Clercq, E.; Liu, X. Synthesis and biological evaluation of pyridazine derivatives as novel HIV-1 NNRTIs. Bioorg. Med. Chem. 2013, 21, 2128-2134. [CrossRef] [PubMed]

155. Mantu, D.; Antoci, V.; Mangalagiu, I.I. Design, synthesis and antimycobacterial activity of some new pyridazine derivatives: Bis-pyridazine. Part IV 12-14. Infect. Disord. Drug Targets 2013, 13, 344-351. [CrossRef] [PubMed]

156. Guan, L.P.; Sui, X.; Deng, X.Q.; Quan, Y.C.; Quan, Z.S. Synthesis and anticonvulsant activity of a new 6-alkoxy-[1,2,4]triazolo[4,3-b]pyridazine. Eur. J. Med. Chem. 2010, 45, 1746-1752. [CrossRef] [PubMed]

157. Sivakumar, R.; Anbalagan, N.; Gunasekaran, V.; Leonard, J.T. Synthesis and anticonvulsant activity of novel 1-substituted-1,2-dihydro-pyridazine-3,6-diones. Biol. Pharm. Bull. 2003, 26, 1407-1411. [CrossRef] [PubMed]

158. Moreau, S.; Coudert, P.; Rubat, C.; Gardette, D.; Vallee-Goyet, D.; Couquelet, J.; Bastide, P.; Tronche, P. Synthesis and anticonvulsant properties of new benzylpyridazine derivatives. J. Med. Chem. 1994, 37, 2153-2160. [CrossRef] [PubMed]

159. Sapa, J.; Zygmunt, M.; Kulig, K.; Malawska, B.; Dudek, M.; Filipek, B.; Bednarski, M.; Kusak, A.; Nowak, G. Evaluation of anticonvulsant activity of novel pyrrolidin-2-one derivatives. Pharmacol. Rep. 2014, 66, 708-711. [CrossRef] [PubMed]

160. Sapa, J.; Filipek, B.; Kulig, K.; Malawska, B. Antidepressant-like activity of the phenylpiperazine pyrrolidin-2-one derivatives in mice. Pharmacol. Rep. 2011, 63, 71-78. [CrossRef]

161. Nevagi, R.J.; Dhake, A.S.; Narkhede, H.I.; Kaur, P. Design, synthesis and biological evaluation of novel thiosemicarbazide analogues as potent anticonvulsant agents. Bioorg. Chem. 2014, 54, 68-72. [CrossRef] [PubMed]

162. Dawidowski, M.; Turło, J. Multicomponent synthesis and anticonvulsant activity of monocyclic 2,6-diketopiperazine derivatives. Med. Chem. Res. 2014, 23, 2007-2018. [CrossRef] [PubMed]

163. Strupińska, M.; Rostafińska-Suchar, G.; Pirianowicz-Chaber, E.; Stables, J.P.; Jiang, J.; Paruszewski, R. Synthesis and research of benzylamides of some isocyclic and heterocyclic acids as potential anticonvulsants. Acta Pol. Pharm. 2013, 70, 681-686. [PubMed]

164. Pastore, V.; Sabatier, L.; Enrique, A.; Marder, M.; Bruno-Blanch, L.E. Synthesis and anticonvulsant activity of bioisosteres of trimethadione, $N$-derivative-1,2,3-oxathiazolidine-4-one-2,2-dioxides from $\alpha$-hydroxyamides. Bioorg. Med. Chem. 2013, 21, 841-846. [CrossRef] [PubMed]

165. Uysal, S.; Calis, U.; Soyer, Z. Synthesis and anticonvulsant activity of some 2/3-benzoylaminopropionanilide derivatives. Arzneimittelforschung 2012, 62, 295-300. [CrossRef] [PubMed]

166. Guan, L.P.; Wei, C.X.; Deng, X.Q.; Sui, X.; Piao, H.R.; Quan, Z.S. Synthesis and anticonvulsant activity of N-(2-hydroxyethyl) cinnamamide derivatives. Eur. J. Med. Chem. 2009, 44, 3654-3657. [CrossRef] [PubMed]

167. Alswah, M.; Ghiaty, A.; El-Morsy, A.; El-Gamal, K. Synthesis and Biological Evaluation of Some $[1,2,4]$ triazolo[4,3-a]quinoxaline Derivatives as Novel Anticonvulsant Agents. ISRN Org. Chem. 2013, 2013. [CrossRef] [PubMed] 
168. Chen, J.; Sun, X.Y.; Chai, K.Y.; Lee, J.S.; Song, M.S.; Quan, Z.S. Synthesis and anticonvulsant evaluation of 4-(4-alkoxylphenyl)-3-ethyl-4H-1,2,4-triazoles as open-chain analogues of 7-alkoxyl-4,5dihydro[1,2,4]triazolo[4,3-a]quinolines. Bioorg. Med. Chem. 2007, 15, 6775-6781. [CrossRef] [PubMed]

169. Wang, S.B.; Jin, P.; Li, F.N.; Quan, Z.S. Synthesis and anticonvulsant activity of novel purine derivatives. Eur. J. Med. Chem. 2014, 84, 574-583. [CrossRef] [PubMed]

170. Shu, B.; Zheng, Y.; Wang, S.B.; Deng, X.Q.; Quan, Z.S. Design, synthesis, and anticonvulsant activity evaluation of 4-(3-alkoxy-phenyl)-2,4-dihydro-[1,2,4]triazol-3-ones. Arch. Pharm. 2013, 346, 127-133. [CrossRef] [PubMed]

171. Kahveci, B.; Menteşe, E.; Akkaya, E.; Yılmaz, F.; Doğan, I.S.; Ozel, A. Synthesis of some novel 1,2,4-triazol-3-one derivatives bearing the salicyl moiety and their anticonvulsant activities. Arch. Pharm. 2014, 34, 449-455. [CrossRef] [PubMed]

172. Deng, X.Q.; Wei, C.X.; Li, F.N.; Sun, Z.G.; Quan, Z.S. Design and synthesis of 10-alkoxy-5,6dihydro-triazolo[4,3-d]benzo[f][1,4]oxazepine derivatives with anticonvulsant activity. Eur. J. Med. Chem. 2010, 45, 3080-3086. [CrossRef] [PubMed]

173. Piao, F.Y.; Peng, B.; Zhang, W.B.; Zhang, W.; Han, R.B. Synthesis and biological evaluation of 9-alkoxy-6,7-dihydro-5H-benzo[c][1,2,4]triazolo[4,3-a]azepines as potential anticonvulsant agents. Arzneimittelforschung 2012, 62, 202-207. [CrossRef] [PubMed]

174. Deng, X.Q.; Song, M.X.; Wang, S.B.; Quan, Z.S. Synthesis and evaluation of the anticonvulsant activity of 8-alkoxy-4,5-dihydrobenzo[b][1,2,4]triazolo[4,3-d][1,4]thiazepine derivatives. J. Enzym. Inhib. Med. Chem. 2014, 29, 272-280. [CrossRef] [PubMed]

175. Ulloora, S.; Shabaraya, R.; Ranganathan, R.; Adhikari, A.V. Synthesis, anticonvulsant and anti-inflammatory studies of new 1,4-dihydropyridin-4-yl-phenoxyacetohydrazones. Eur. J. Med. Chem. 2013, 70, 341-349. [CrossRef] [PubMed]

176. Siddiqui, N.; Ahsan, W.; Alam, M.S.; Ali, R.; Srivastava, K. Design, synthesis and evaluation of anticonvulsant activity of pyridinyl-pyrrolidones: A pharmacophore hybrid approach. Arch. Pharm. 2012, 345, 185-194. [CrossRef] [PubMed]

177. Lee, H.; Park, K.D.; Torregrosa, R.; Yang, X.F.; Dustrude, E.T.; Wang, Y.; Wilson, S.M.; Barbosa, C.; Xiao, Y.; Cummins, T.R.; Khanna, R.; Kohn, H. Substituted N-(biphenyl-4'-yl) methyl (R)-2-acetamido-3-methoxypropionamides: Potent anticonvulsants that affect frequency (use) dependence and slow inactivation of sodium channels. J. Med. Chem. 2014, 57, 6165-6182. [CrossRef] [PubMed]

178. Siddiqui, N.; Arshad, M.F.; Khan, S.A.; Ahsan, W. Sulfonamide derivatives of thiazolidin-4-ones with anticonvulsant activity against two seizure models: Synthesis and pharmacological evaluation. J. Enzym. Inhib. Med. Chem. 2010, 25, 485-491. [CrossRef] [PubMed]

179. Hen, N.; Bialer, M.; Yagen, B. Syntheses and evaluation of anticonvulsant activity of novel branched alkyl carbamates. J. Med. Chem. 2012, 55, 2835-2845. [CrossRef] [PubMed]

180. Hen, N.; Bialer, M.; Wlodarczyk, B.; Finnell, R.H.; Yagen, B. Syntheses and evaluation of anticonvulsant profile and teratogenicity of novel amide derivatives of branched aliphatic carboxylic acids with 4-aminobenzensulfonamide. J. Med. Chem. 2010, 53, 4177-4186. [CrossRef] [PubMed]

181. Guan, L.P.; Zhao, D.H.; Xiu, J.H.; Sui, X.; Piao, H.R.; Quan, Z.S. Synthesis and anticonvulsant activity of N-(2-hydroxy-ethyl)amide derivatives. Arch. Pharm. 2009, 342, 34-40. [CrossRef] [PubMed]

182. Senthilraja, M.; Alagarsamy, V. Synthesis and pharmacological investigation of 2-(4-dimethylaminophenyl)-3,5-disubstituted-thiazolidin-4-ones as anticonvulsants. Arch. Pharm. 2012, 345, 827-833. [CrossRef] [PubMed]

(C) 2015 by the authors; licensee MDPI, Basel, Switzerland. This article is an open access article distributed under the terms and conditions of the Creative Commons by Attribution (CC-BY) license (http://creativecommons.org/licenses/by/4.0/). 